\title{
New Cixiidae from Eastern Polynesia: Oteana gen.nov. and Manurevana gen. nov. (Hemiptera: Fulgoromorpha)
}

\author{
HANNELORE HOCH
}

Humboldt University, Museum für Naturkunde, Invalidenstr. 43, D-10115 Berlin, Germany. E-mail: hannelore.hoch@museum.hu-berlin.de

\section{Table of contents}

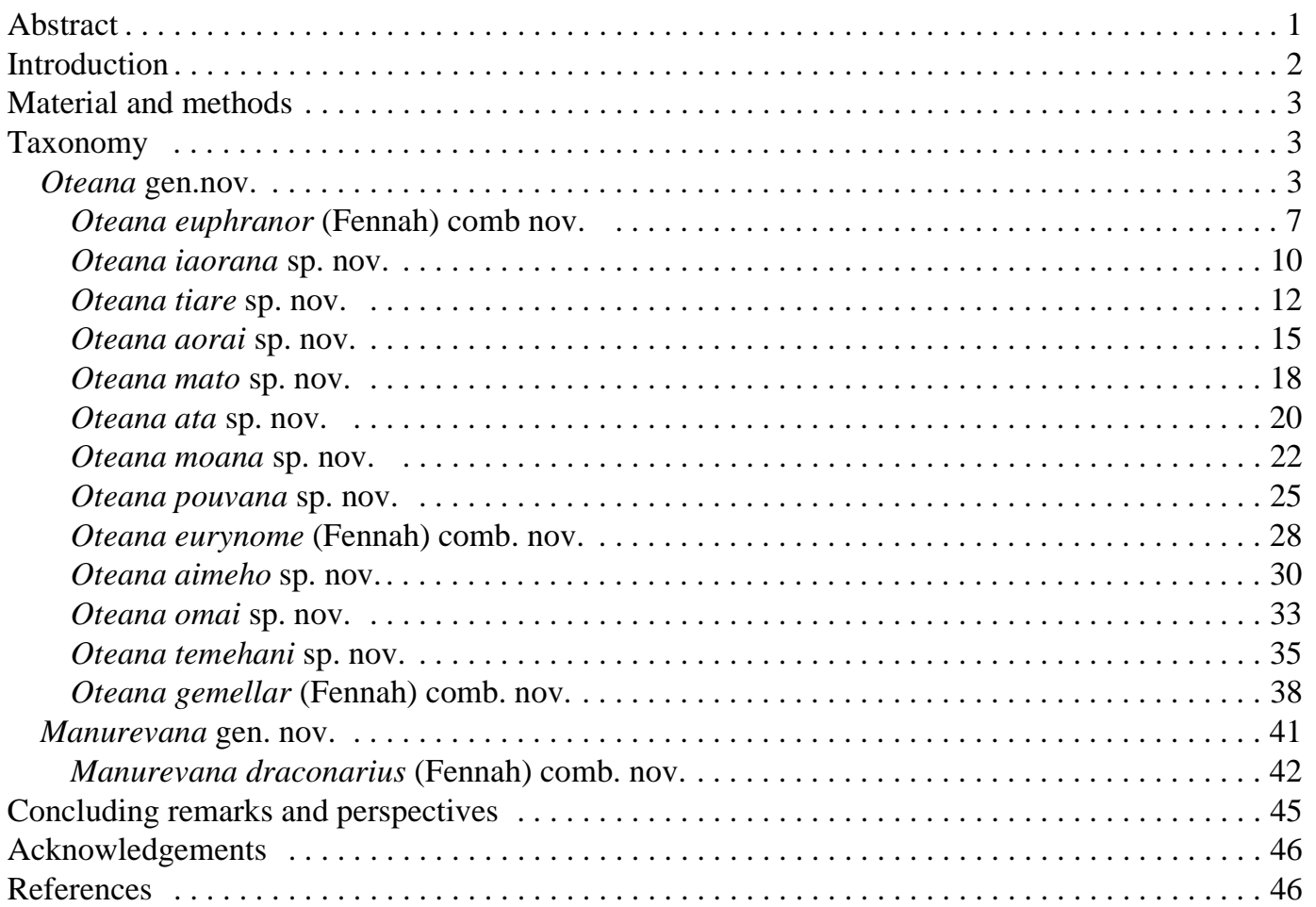

\begin{abstract}
Two new genera are established to accommodate the cixiid species from the Society, Austral and Cook Islands formerly assigned to the genus Oliarus Stål: 1. Oteana gen.nov. with the type species Oteana euphranor (Fennah) comb.nov. from Tahiti, Oteana eurynome (Fennah, 1958) comb. nov.
\end{abstract}


from Moorea, and Oteana gemellar (Fennah, 1958) comb. nov. from Rarotonga (Cook Islands); additionally, ten new Oteana species are described from the Society Islands: Oteana iaorana sp. nov., O. tiare sp. nov., O. aorai sp. nov., O. mato sp. nov., O. ata sp. nov., O. moana sp. nov., and $O$. pouvana sp. nov., all from Tahiti, as well as $O$. aimeho sp. nov. from Moorea, $O$. omai sp. nov. from Huahine, and $O$. temehani sp. nov. from Raiatea. 2. Manurevana gen. nov. with the type species Manurevana draconarius (Fennah, 1958) comb. nov. Notes on their ecology and distribution are given.

Key words: taxonomy, Pacific region, radiation

\section{Introduction}

Cixiidae of the tribe Pentastirini have colonized several Pacific island archipelagos. In some cases colonizing lineages have given rise to a considerable number of species as a result of rapid speciation and (adaptive) radiation, e.g., in the Hawaiian (91 species and subspecies) and the Marquesas Islands (18 species) (Giffard 1925, Zimmermann 1948, Fennah 1958, 1973, Hoch \& Howarth 1999). Although roughly comparable with these in age and ecological diversity (Craig et al. 2001), the Society, Austral, and Cook Islands appeared to harbour a far lower number of cixiid species. Only 4 species were known: Oliarus euphranor Fennah, 1958 from Tahiti, Oliarus eurynome Fennah, 1958 from Moorea, Oliarus gemellar Fennah, 1958 from the Cook Islands: Rarotonga, and Oliarus draconarius Fennah, 1958 from the Austral Islands: Rurutu (Fennah 1958).

All Pentastirini from the central Pacific islands were previously assigned to the (then) worldwide distributed catch-all genus Oliarus Stål, 1862. Already in 1958, Fennah stated: "As defined at present, it includes an easily recognized group of insects, but which is by no means homogenous, and which falls into species-groups which are more or less distinct from one another" (Fennah 1958: 123). Subsequently, various authors, e.g., Van Stalle (1986 a-c), Emeljanov (2001a, b) erected several genera to better reflect this heterogeneity. Many species, however, including most of the central Pacific island Pentastirini, remained in Oliarus, with the exception of the Hawaiian species for which Holzinger et al. (2002) resurrected Nesoliarus Kirkaldy, 1909.

In a recent publication (Hoch 2005) the genus Oliarus was re-defined based on the examination of the type species, Oliarus walkeri (Stål, 1859).

Recent research in the field and the examination of existing collections revealed:

1. the pentastirine diversity at least in the Society Islands is far higher than previously assumed: in addition to the 2 known species from the Society Islands, 10 new species are described below: 7 from Tahiti, 1 from Moorea, 1 from Huahine, and 1 from Raiatea.

2. None of the species from the Society, Cook, and Austral Islands belong to Oliarus s.str. Instead, they are representatives of two distinct morphological groups, neither of which can be placed into any of the existing pentastirine genera.

Therefore, two new genera are established: Oteana gen. nov. to accommodate the 
species from the Society and Cook Islands, and Manurevana gen. nov. for O. draconarius

\section{Material and methods}

The specimens were preserved dry or in ethanol. For dissection of the male genitalia, dry preserved specimens were softened in acetic acid atmosphere for 3-4 hours, until intersegmental membranes could be easily manipulated. The genital capsule was then removed, transferred to $10 \% \mathrm{KOH}$ and macerated at room temperature for 24 hours while the specimen was card-mounted. Drawings of genitalia (while in glycerine-jelly) and external characters were made using a camera lucida and a standard Leitz stereomicroscope. Genitalia are stored in glycerine in a plastic vial pinned underneath the specimen, or in the case of specimens preserved in ethanol, plastic vials containing the genitalia associated with the vials containing the specimens.

Measurements pertaining to body length equal the distance between apex of head and tip of tegmina.

Depositories of material are as follows: MNHN (Musée national d'Histoire naturelle, Paris, France), BPBM (Bishop Museum, Honolulu, Hawaii, U.S.A), and AH (collection of M. Asche and H. Hoch, Museum für Naturkunde, Berlin, Germany).

\section{Taxonomy}

\section{Oteana gen. nov.}

Type species: Oliarus euphranor Fennah, 1958: 131, Society Islands: Tahiti (Mt. Aorai)

\section{Description}

Habitus (fig. 1). Small to medium size cixiids (males 4.9-8.0 mm, females 5.5-9.0 $\mathrm{mm}$ ) with moderately depressed body form, mesonotum pentecarinate, tegmina shallowly tectiform, translucent.

Head (figs 2-4)

Vertex long, narrow, ca. 1.5 times as long as posteriorly wide, in dorsal aspect surpassing the anterior margin of the compound eyes with ca. 1/3 its total length; lateral carinae ridged, converging anteriorly; median carina obsolete; posterior margin of vertex medially deeply incised. Areolets divided by a short robust median carina. Frons separated from vertex by a distinct transverse carina. Frons ca. 1.8 times as wide as medially long, widest at level of the antennae. Lateral ocelli distinct, median frontal ocellus present yet obsolete. Frontoclypeal suture parabolic. Frons and clypeus with a distinct median carina which forks towards the apex. Rostrum in repose attaining metatrochanters.

Antennae small, not visible in dorsal aspect. $1^{\text {st }}$ antennal segment short, ring-like, $2^{\text {nd }}$ antennal segment globose, irregularly beset with sense organs (plaques). 


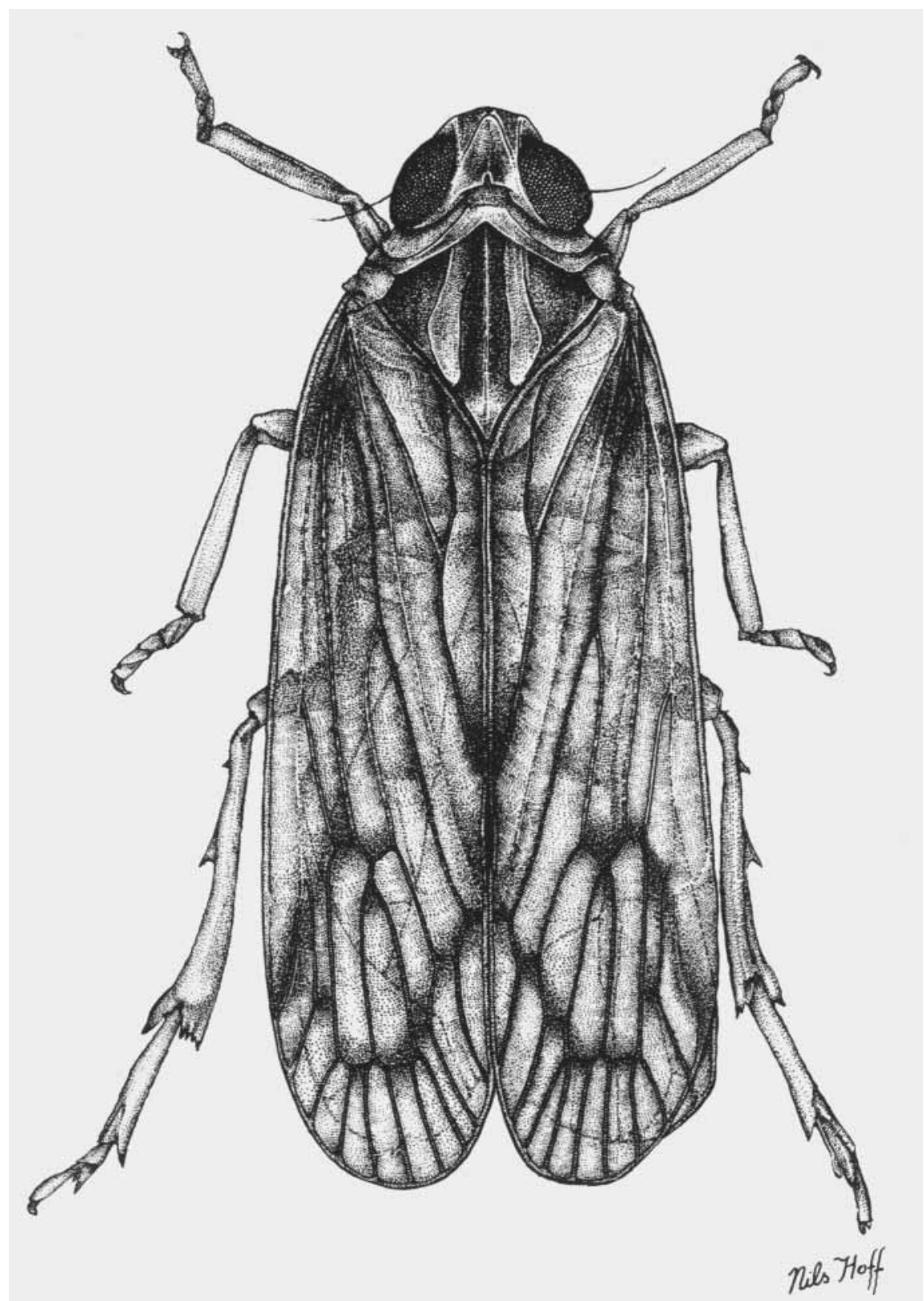

FIGURE 1. Habitus of Oteana. Oteana spec., female.

\section{Thorax}

Pronotum short, posterior margin deeply incised, only slightly wider than head, with distinct median and lateral carinae. Mesonotum pentecarinate, ca. 1.2 times as wide as medially long. 


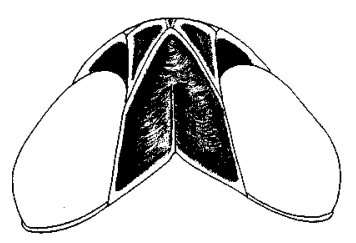

2
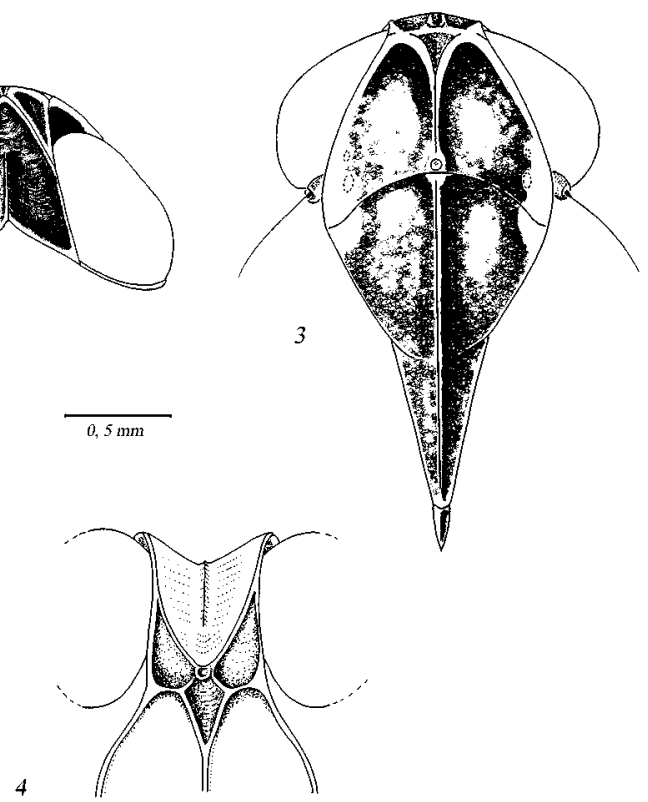

FIGURES 2-4. Oteana gen.nov. (O. euphranor (Fennah, 1958), male): head. 2. Vertex, dorsal aspect; 3. Frons and clypeus, ventral aspect; 4. transition vertex/frons with areolets, anterior aspect. Scale bar equals $0.5 \mathrm{~mm}$.

Tegmina and wings well developed. Tegmina shallowly tectiform, in repose surpassing tip of abdomen with ca. 1/4 their total length. Tegmen (fig. 5) ca. 3.2 times longer than maximally wide. Apex of outer subapical cell slightly distad of apex of inner subapical cell. Intercubital transverse veinlet entering margin of tegmen distinctly distad of claval suture. Longitudinal veins inconspicuously granulate.

Legs (fig. 6) Metatibiae laterally generally with 3 small spines (except for the species from Moorea which display 1 and 2-3 spines, respectively), apically with 6 spines ( 5 arranged in an oblique row, lateral spine more strongly pronounced). Metabasitarsus ca. 1.5 times longer than $2^{\text {nd }}$ and $3^{\text {rd }}$ metatarsal joints together, distally with 7 spines in a slightly arched row (lateral spines are longest), $2^{\text {nd }}$ metatarsal joint distally with 5 spines. Metatarsal joints without macrochaetae (platellae).

Male genital complex

Genital segment with laterodorsal margins strongly produced caudad in a subrectangular lobe with dorsal apical angles on the right or/and the left side more or less acute; thus, genital segment either bilaterally symmetrical or asymmetrical. Medioventral process in ventral aspect triangular, with fine lateral grooves converging ventrocaudally. Anal segment in dorsal aspect highly or broadly ovate, in most species bilaterally symmetrical. Parameres slender at base, with median portion bulging, apically produced dorsolaterally, in lateral aspect hook-shaped; mediodorsal margin more or less serrate. Aedeagus (fig. 7) with shaft and flagellum well developed. Shaft ventrally and apically with a characteristic set of spines. Inter- and intraspecific variation is observed in the configuration of these spines. Flagellum long, in repose bent dorsobasad to the left side. Flagellum membranous, with a few more strongly sclerotized portions: at least one distal 
spine (fig. 7, b1) and a ventral, more or less triangular ridge near flagellum bend (fig 7, b2). Phallotreme at apex of flagellum (fig. 7, b3). To point out hypothesized homologous structures of the aedeagus in the species of Oteana, the same indications used in fig. 7 are referred to in the individual species descriptions.
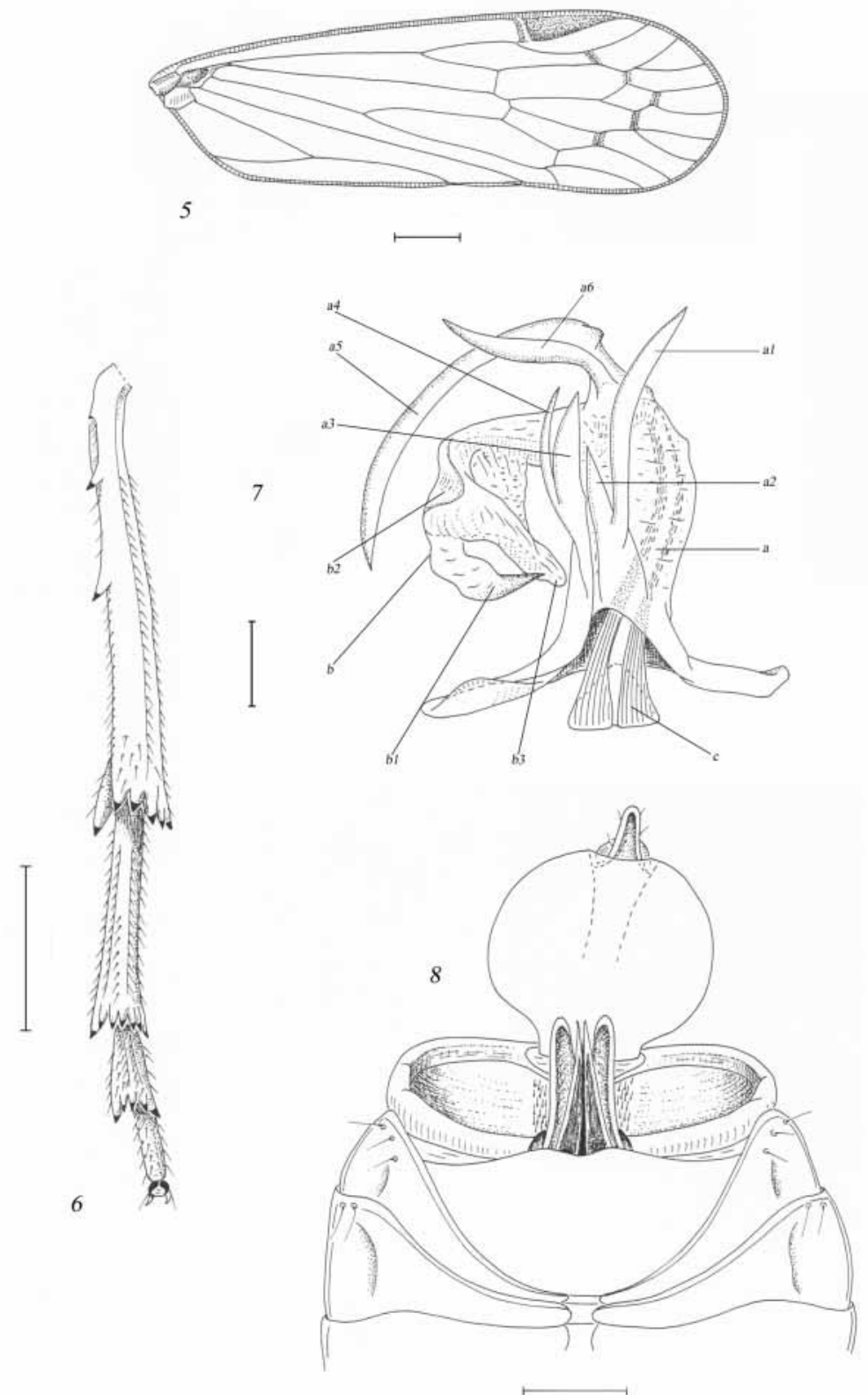

FIGURES 5-8. Oteana gen. nov. : 5. right tegmen (O. euphranor, female); 6. right hindleg, ventral aspect $(O$. euphranor, female); 7. configuration of the male copulatory organ, the aedeagus $(O$. mato $)$; 8 . external aspects of female genitalia (Oteana spec.). Scale bars equal $0.5 \mathrm{~mm}$ (figs $5,6,8$ ) and $0.1 \mathrm{~mm}$ (fig. 7).

Abbreviations: a, shaft ("periandrium" sensu Giffard 1925); b, flagellum ("phallus" sensu Giffard 1925); c, central part ("apodeme of phallus" sensu Giffard 1925); a1-a4, ventral spines of shaft (a1, right lateral spine; a2, median right spine; a3, median left spine; a4, left lateral spine); a5, apical shaft spine; a6, subapical shaft spine; b1, distal flagellum spine; b2, sclerotized ridge of flagellum; b3, phallotreme ("functional orifice" sensu Giffard 1925). 
Female genitalia (fig. 8)

Caudal margin of 7th sternite shallowly sinuate, medially slightly concave. Ovipositor

short, stout, in repose directed straight caudad. $9^{\text {th }}$ tergite truncate, caudally concave, with wax producing area distinct, medially not divided. Anal segment plate-shaped, ventrally concave, wide at base. Ductus receptaculi tubular, not heliciform.

Etymology

Named after the traditional drum dance from Tahiti, the Otea. The gender is feminine.

Remarks

Oteana can be distinguished from other pentastirine genera by bodily proportions, shape and arrangement of spines of the metatarsi (7, 5, no platellae), and especially by the configuration of the male genitalia (arrangement of ventral and apical aedeagal shaft spines).

Oteana euphranor (Fennah) comb. nov.

(figs 9-15)

Oliarus euphranor Fennah 1958: 131

Supplementary description.

Body length.

Male. 4.9-5.4 mm (+/- 0.172), $\mathrm{n}=15$. Female. 5.5-6.2 mm (+/- 0.188), $\mathrm{n}=25$.

Coloration.

Area of vertex, areolets, frons, and clypeus dark brown, carinae of head and fenestrae stramineous. Pronotum with discoidal and ventral areas dark brown, posterior margin and carinae stramineous. Tegulae testaceous. Mesonotum dark brown to blackish, longitudinal carinae generally lighter, more or less contrasting, posterior tip of mesonotum stramineous. Tegmina and wings hyaline, translucent, without conspicuous pattern. Costal vein dark brown, pterostigma distinct, dark brown. Venation of tegmina otherwise testaceous, slightly darker in apical third.

Proportions and carination of head and thorax as well as spinulation of hind legs as described for the genus. 

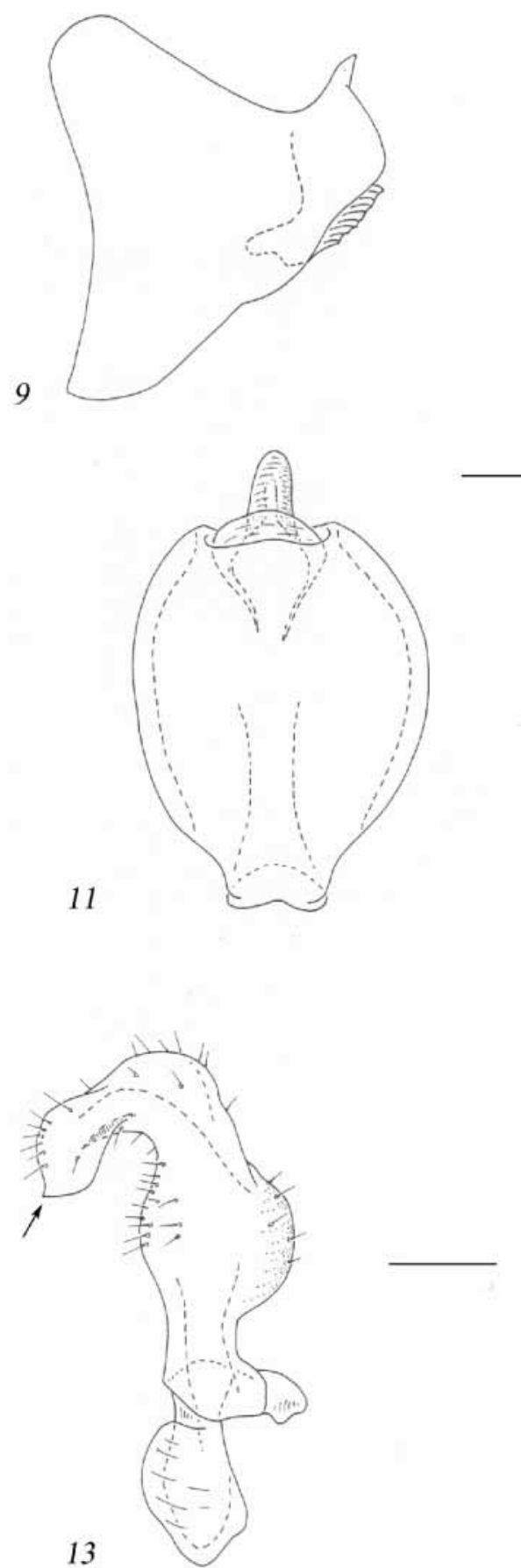
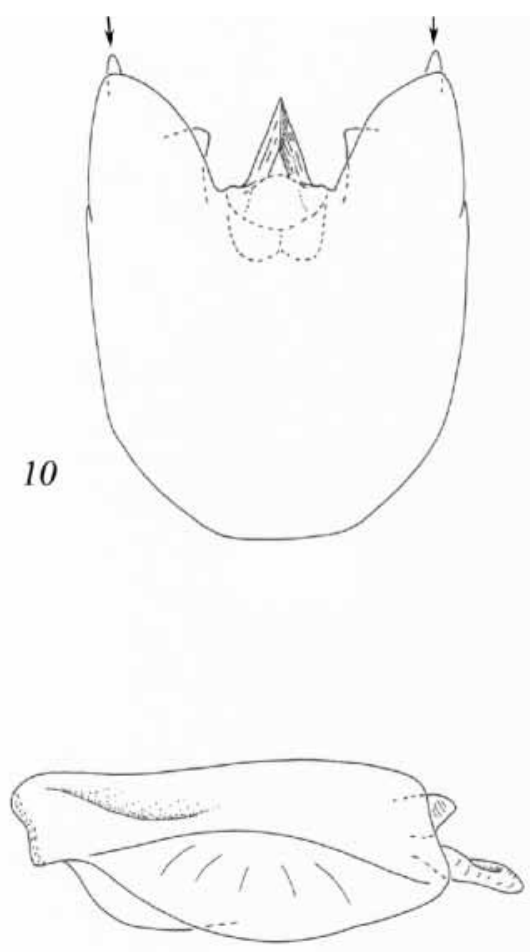

12

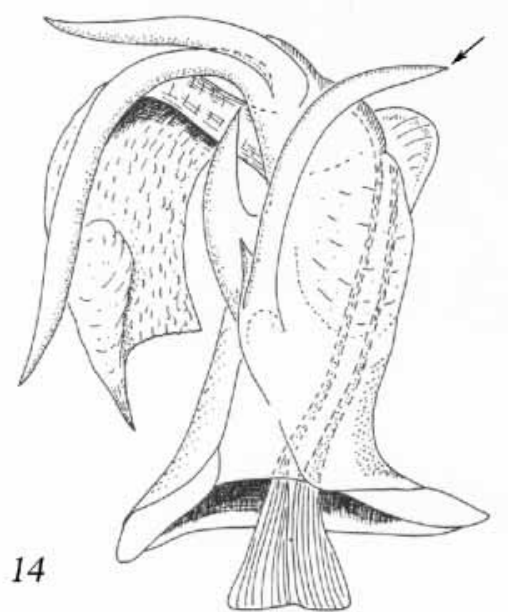

FIGURES 9-14. Oteana euphranor (Fennah, 1958). Male genitalia. 9, genital segment, left lateral aspect; 10, same, ventral aspect; 11, anal segment, dorsal aspect; 12, same, left lateral aspect; 13, left paramere, maximal aspect; 14, aedeagus, ventral aspect; Scale bars equal $0.1 \mathrm{~mm}$. 
Male genital complex (figs 9-15)

Genital segment (figs 9, 10) bilaterally symmetrical, with both dorsal apical angles of subrectangular lobes acute; medioventral process gradually tapering posteriorly. Anal segment (figs 11,12 ) symmetrical, elongately ovate. Parameres distally produced into a pointed tip (fig 13, arrow). Aedeagus (figs 14, 15): shaft dorsally with a rounded, earshaped protrusion (fig 14, arrow), ventrally with 3 spines: right lateral spine (a1) long, slender, terete, curved laterad to the right side; median spine (a2?) short, pointed, directed straight caudad; left spine (a3) strong, inserting with a broad base, apically tapering, directed caudad. Left spine variable within populations (fig 15), unforked (in most specimens studied) or forked. Apical spine of shaft (a5) long, slender, terete, curved laterobasad to the left side, almost reaching tip of flagellum. Subapical spine (a6) comparatively short, slightly curved, directed left laterad. Flagellum simple, with one distinct distal spine (b1).

Female genitalia as described for the genus.
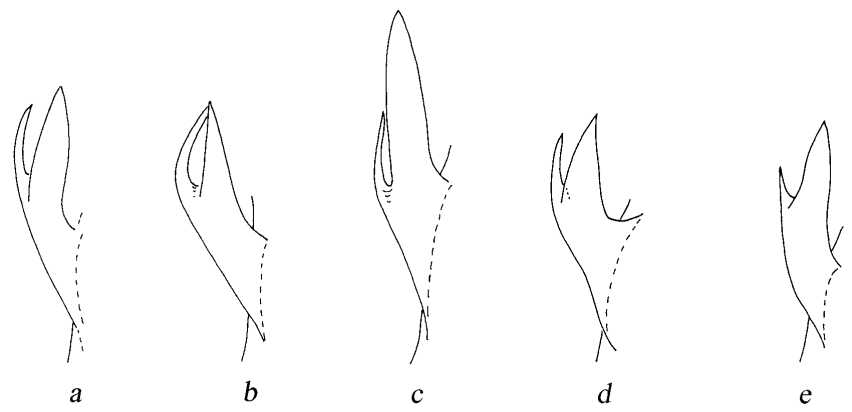

FIGURE 15. Oteana euphranor (Fennah, 1958). Male genitalia. Variation of left lateral (ventral) spine of aedeagus shaft (a4): a-d, from population on Mt. Aorai, Tahiti Nui, e, specimen from Vaiufaufa, Tahiti Iti. Scale bar equals $0.1 \mathrm{~mm}$.

Distribution

Endemic to Tahiti (Tahiti Nui: Mt Aorai, Mt. Marau, Pico Vert, and Tahiti Iti). Most common Oteana species.

Ecology

On native vegetation. Likely host plants are Weinmannia parviflora (Cunoniaceae) (Fennah 1958), Metrosideros collina (Myrtaceae), Myrsine spec. (Myrsinaceae). From $800-$ above $1600 \mathrm{~m}$.

Material examined

Holotype $o^{\star}$ (here re-examined): Society Islands: Tahiti I., Mt. Aorai Trail, 4500-5500 ft, E.C. Zimmerman leg., BPBM (type nr 2628). 
Additional material: all specimens from Tahiti Island.

Mt. Aorai: 109 ox, 66 ㅇ, Mt. Aorai Trail, between 600-ca.1650 m, native vegetation: Weinmannia parviflora, Metrosideros collina, Coprosma spec., Dodonaea viscosa, ferns, 14.IV.-12.V.1999, M. Asche \& H. Hoch, AH; $120^{\star}$, 2우, ibid., 1400m, 12.IX.1977, at light, S.L. Montgomery, BPBM Acc.Nr. 1977.361; 31 o $^{\star}, 15$ 우, Mt. Aorai, NW Ridge, 800-1450 $\mathrm{m}$, , native vegation, Metrosideros collina, Weinmannia parviflora, Vaccinium cereum, Styphelia tameiameia var. sacretalis, Reynoldsia verrucosa, 9.VII. -11.VII.1961, J.L. Gressitt, BPBM; 3 o, 1 우, Mt. Aorai, N-side, 1400m, at light, W.C. Gagné \& S.L. Montgomery, BPBM Acc.Nr. 1977.361.

Mt. Marau: $1 \sigma^{x}, 3$ ㅇ, $\mathrm{N}$ side of Mt. Marau, 1300-1400 m, ex Weinmannia, 15.III.1983, G. Paulay, BPBM; 1 ơ 1 ㅇ, Mt. Marau, 1200-1300 m, ex Weinmannia, 29.30.VIII.1984, G. Paulay, BPBM Acc.nr. 1985.69; 3 ơ, ibid., 1300m, 29.VIII.1984, G. Paulay, BPBM Acc.nr. 1985.69; 2 ox, 5 ㅇ, ibid., 1300-1400m, beaten from Weinmannia, 28.VIII.1984, G. Paulay, BPBM Acc.nr. 1985.69; 1 o $^{x}$, road to Mt Marau, 840-850m, 29.VIII.1977, at light, W.C. Gagné \& S.L. Montgomery, BPBM Acc.nr. 1977-361; 1 ơ, ibid., 950-960 m, native forest, 27.VIII.1977, W.C. Gagné, BPBM; 1 ox, Mt. Marau, 1000m, 19.-21.VIII.1977, S.L. Montgomery, BPBM Acc.Nr. 1983.25; 1 o , ibid., 1490 m, 19.-21.VIII.1977, S.L. Montgomery, BPBM Acc.Nr. 1983.25; 4 o , ibid., $1490 \mathrm{~m}$, on Myrsine and Weinmannia, 29.-30.VI. 1977, W.C.Gagné, BPBM Acc.nr. 1977.361; 1 o $^{x}$, ibid., 1400-1500m, on Weinmannia parviflora, 18.-21.VIII.1977, W.C. Gagné, BPBM; 15 o $^{x}, 6$ ㅇ․, Mt. Marau, 1430 m, ex Weinmannia, 3.IX. 2004, D. M. Percy, BPBM; 1 o $^{x} 1$ ㅇ, ibid, 1430 m, ex Weinmannia, 13.IX. 2004, D.M. Percy, BPBM.

Pico Vert: 1 ơ, 1 ㅇ, Pico Vert, ca. 800 m, ex Metrosideros collina, 6.VI.2002, D. M. Percy, BPBM.

Tahiti Iti: $9 \circ^{\star}$, Taiarapu, above Vaiufaufa, 900m, 24.-25.IX.1977, S.L. Montgomery, BPBM Acc.nr. 1977.361; 7 o, ibid., 900 m, 3.VII.1977, S.L. Montgomery, BPBM Acc.nr. 1977.361; 1 ox, Vaiufaufa, 500 m, 1. IV.1971, N.L.H. Krauss, BPBM.

\section{Oteana iaorana sp. nov.}

(figs 16-21)

Description.

Body length.

Male. $6.2-6.3 \mathrm{~mm} ; \mathrm{n}=2$.

Coloration.

Head and thorax as in O. euphranor.. Legs stramineous, ventrally dark brown. Tegmina hyaline, translucent, proximally smoky brown, especially around the Y-vein. Costal vein proximad of junction with Y-vein dark brown over a short distance.

Proportions and carination of head and thorax as well as spinulation of hind legs as described for the genus, slightly larger than $O$. euphranor. 

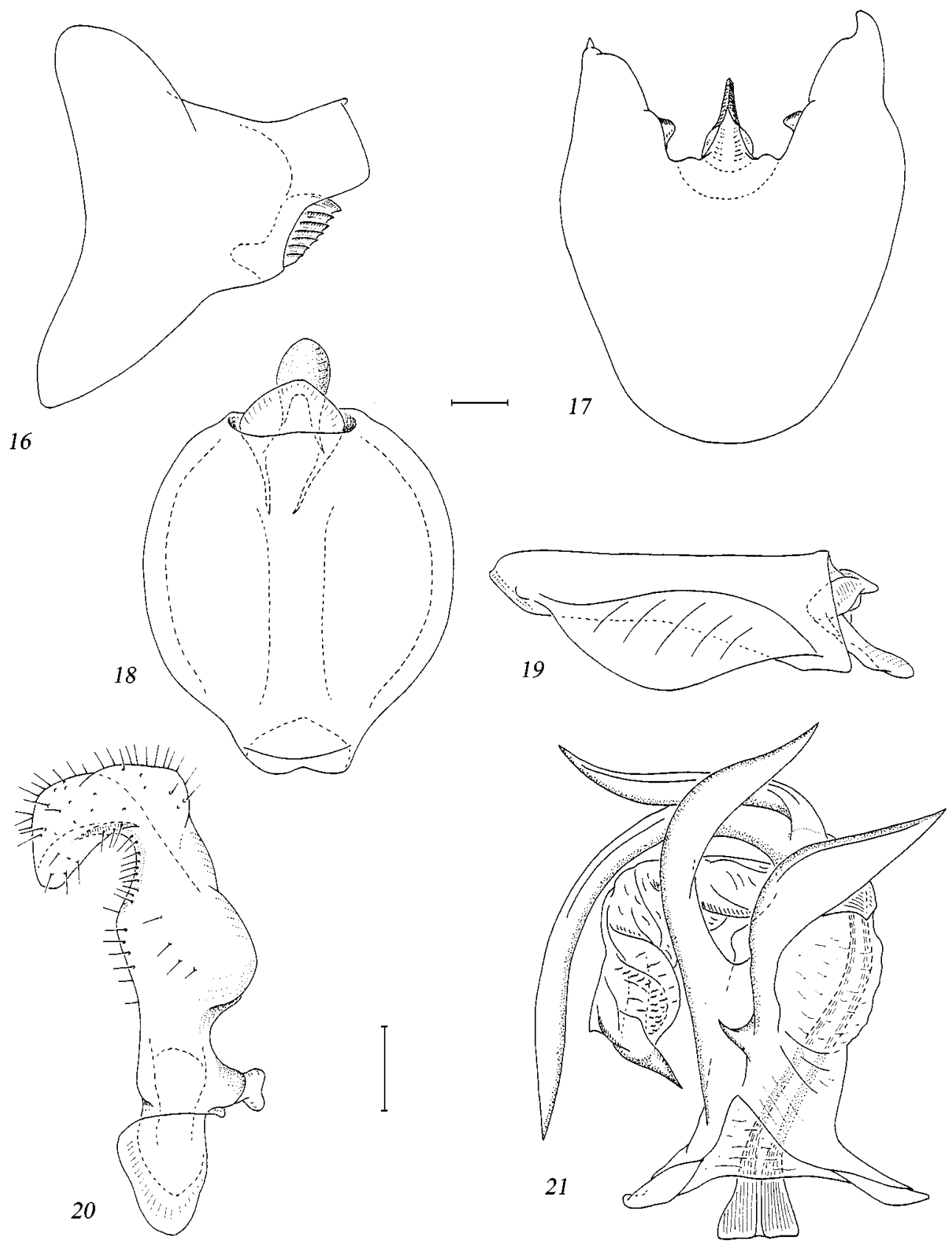

FIGURES 16-21. Oteana iaorana sp.nov., holotype. Male genitalia. 16, genital segment, left lateral aspect; 17, same, ventral aspect; 18, anal segment, dorsal aspect; 19, same, left lateral aspect; 20, left paramere, maximal aspect; 21, aedeagus, ventral aspect. Scale bars equal $0.1 \mathrm{~mm}$. 
Genital segment (figs 16,17) bilaterally slightly asymmetrical: dorsolateral angle of subrectangular lobe acute on left side, on right side slightly longer, rounded. Anal segment (figs 18,19 ) bilaterally symmetrical, broadly ovate. Parameres (fig. 20) distally produced into a blunt angle, mediodorsal margin serrate. Aedeagus (fig. 21): shaft with 3 ventral spines: right lateral spine (a1) inserting near base, compress, medially distinctly dilated, tapering towards tip, curved laterad to the right side; median spine (a2) inserting near base, short, thorn-like; left lateral spine (a3) of similar shape as spine a1, slightly more slender, strong, compressed, curved laterad to the right side, more or less parallel to right lateral spine; in one specimen with vestigial remnant of spine a4. Apical spine of shaft (a5) long, compress, taeniform, curved laterad to the left side; subapical spine of shaft (a6) ca. half the length of apical spine, compress, sinuate, directed laterad to the left side. Some slight variation among specimens in length of ventral shaft spines. Flagellum in repose nearly reaching base of shaft; distal flagellum spine (b1) present, not strongly sclerotized; in repose directed mediad.

Etymology

"Ia orana" is Tahitian for "hello".

Distribution

Endemic to Tahiti (Tahitit Nui and Tahiti Iti).

Ecology

On native vegetation including Weinmannia parviflora (Cunoniaceae), Metrosideros collina (Myrtaceae), Myrsine spec. (Myrsinaceae). From 900- ca. 1400 m.

Remarks

O. iaorana differs from $O$. euphranor in body size (slightly larger) and particularly in the configuration of the male genitalia: genital segment slightly asymmetrical, and in the arrangement of ventral aedeagal spines.

Type material.

Holotypus ơ: Society Islands: Tahiti I., Taiarapu: above Vaiufaufa, 900 m, 3.VII.1977, at light, S.L. Montgomery, BPBM (type nr. 16616). Paratype: $10^{x}$, Society Islands: Tahiti I., Mt. Aorai Trail, 900-1400m, 16.IV.1999, M.Asche \& H. Hoch, MNHN.

\section{Oteana tiare sp. nov.}

(figs 22-28)

Description

Body length.

Male. 6.5-7.4 mm ( $\mathrm{n}=11)$. Female. $6.6-7.0 \mathrm{~mm}(\mathrm{n}=2)$. 

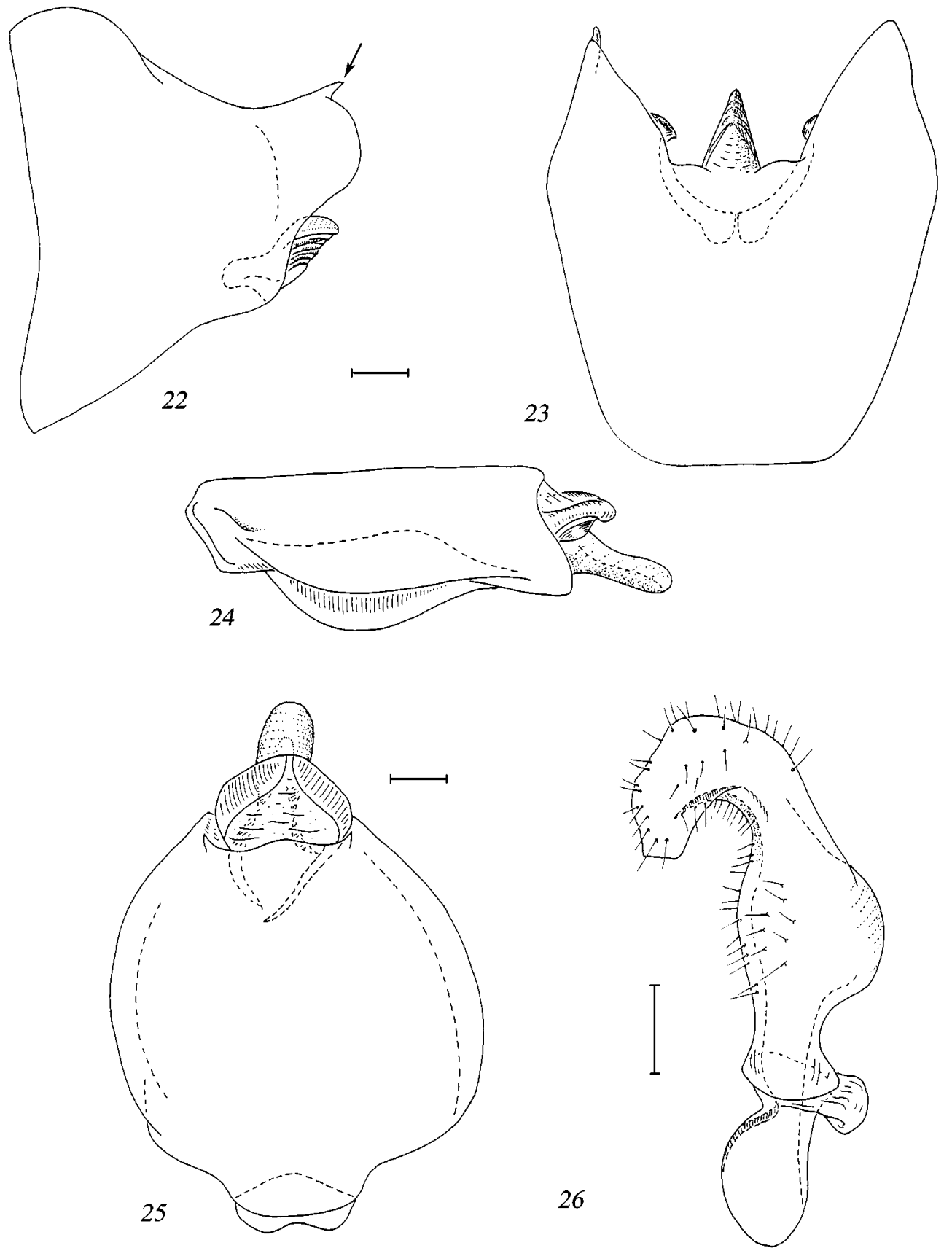

FIGURES 22-26. Oteana tiare sp. nov., holotype. Male genitalia. 22, genital segment, left lateral aspect; 23, same, ventral aspect; 24, anal segment, left lateral aspect; 25, same, dorsal aspect; 26, left paramere, maximal aspect; Scale bars equal $0.1 \mathrm{~mm}$. 

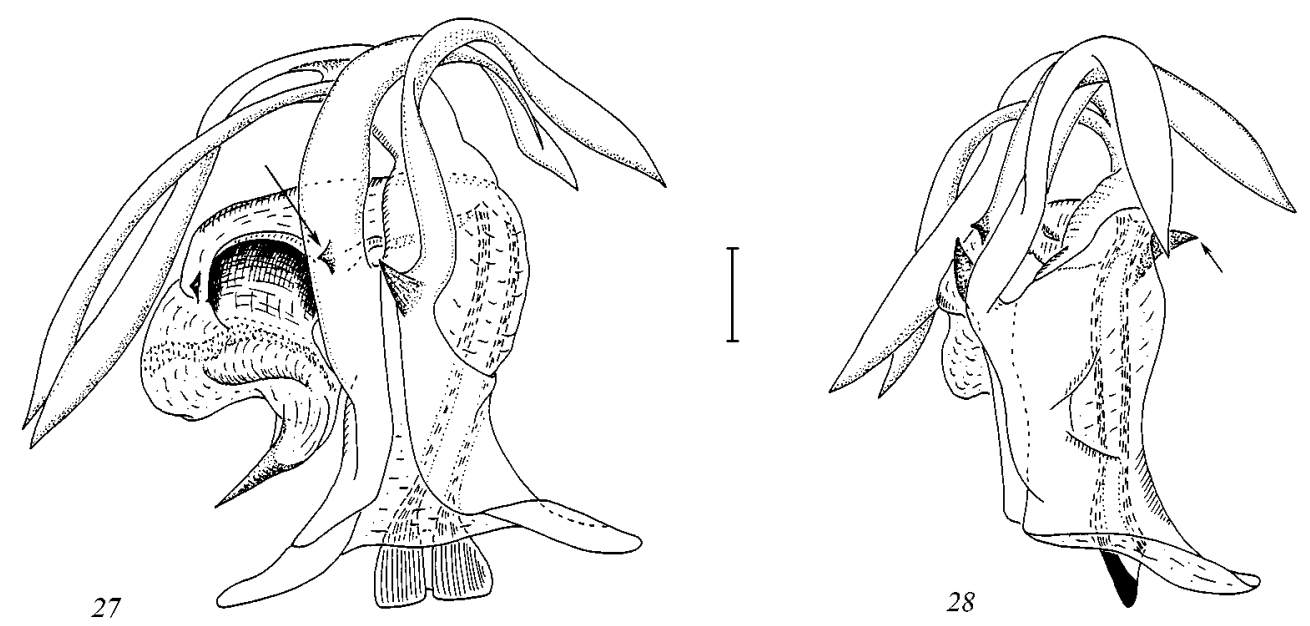

FIGURES 27-28. Oteana tiare sp. nov., holotype. Male genitalia. 27, aedeagus, ventral aspect; 28, same, right lateral aspect. Scale bars equal $0.1 \mathrm{~mm}$.

\section{Coloration.}

Area of vertex, areolets, and frons dark brown, carinae of head stramineous. Fenestrae distinctly colored: a central dark brown spot, surrounded by a lighter fringe. Postclypeus yellowish-orange in male and in female. Pronotum as in O. euphranor. Mesonotum in males dark brown, blackish, longitudinal carinae slightly lighter, in females areas enclosed by lateral carinae on each side stramineous, distinctly contrasting, so that the mesonotum appears longitudinally striped. Venation of tegmina dark brown throughout.

Proportions and carination of head and thorax as well as spinulation of hind legs as described for the genus.

Male genital complex (figs 22-28)

Genital segment (figs 22, 23) bilaterally asymmetrical: dorsolateral angle of subrectangular lobe acute on the left side (fig. 22, arrow), rounded on the right side; medioventral process dorsally ridged. Anal segment (figs 24, 25) slightly asymmetrical. Parameres (fig. 26): distal portion in lateral aspect duckbill-shaped, directed basomediad. Aedeagus (figs 27, 28): shaft ventrally with 2 long, conspicuous spinose processes and 2 minute inconspicuous spines, dorsally with one small, tooth-like spine (fig. 28, arrow), inserting at the transition shaft/flagellum. Long, ventral shaft spines (a1, a3) compressed, taeniform, subapically slightly dilated, almost rectangularly bent laterad to right side, each bearing a small inconspicuous spine (a2, a4: fig. 27, arrow) near its base. Apical (a5) and subapical (a6) spines more or less equally long, arising from a long common base, in repose curved laterobasad. Flagellum in repose not reaching base of shaft, distal flagellum spine (b1) conspicuously sclerotized, acute, directed straight laterad to the left side. Sclerotized ridge of flagellum at midlength produced into a short vestigial spine. 
Etymology

Named for Tiare, the most famous flower of Tahiti, Gardenia taitensis (Rubiaceae).

Distribution

Endemic to Tahiti (Tahiti Nui and Tahiti Iti).

Ecology

On native vegetation including Weinmannia parviflora (Cunoniaceae), Metrosideros collina (Myrtaceae), Myrsine spec. (Myrsinaceae). From 560-1600 m.

Remarks

Oteana tiare differs from all other Oteana species by the yellowish-orange postclypeus and the spine configuration of the aedeagus.

Type material

Holotype ${ }^{x}$, Society Islands: Tahiti I., Taiarapu: above Vaiufaufa [Tahiti Iti], 900 m, 3.VII.1977, at light, S.L. Montogomery, BPBM (type nr 16620).

Paratypes. Tahiti Iti. $4 \sigma^{x}$, same data as holotype; $1 o^{x}$, Society Arch.: Tahiti I., Vaiufaufa viewpoint, 560 m, 7. IX. 1988, at MV light, S.L. Montgomery \& B.H. Gagné, BPBM. Tahiti Nui. Mt. Marau. $1 \sigma^{x}$, Society Is.: Tahiti I.: Mt. Marau, 1490 m, on Myrsine, 29.VI.1977, W.C.Gagné, BPBM Acc.Nr. 1977.361; 1 ox, Society Is.: Tahiti I., Mt. Marau, 1300-1400 m, ex Myrsine, 28.VIII.1984, G. Paulay, BPBM; 1 o`, Society Islands: Tahiti I., Mt. Marau, 1430 m, 13.IX.2004, ex Weinmannia, “*17JG”, D. M. Percy, BPBM; Mt. Aorai. 1 ox, Society Is.: Tahiti I., Mt. Aorai Trail, ca. 600-1200 m, 14.IV.1999, M. Asche \& H.. Hoch, MNHN; $1 \sigma^{x}$, Society Is.: Tahiti I., Mt. Aorai Trail, 1400-1600 m,

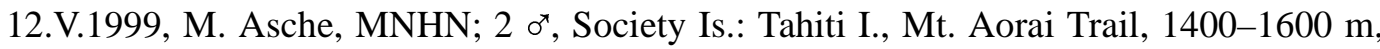
12.V.1999, M. Asche, AH.

Oteana aorai sp. nov.

(figs 29-34)

Description

Body length.

Male. $6.8 \mathrm{~mm}(\mathrm{n}=1)$. Female unknown.

Coloration

Head stramineous, except for area of vertex, areolets, and area enclosed by frontal carina fork, these dark brown. Pronotum as in $O$. euphranor, mesonotum with areas enclosed by lateral carinae on each side stramineous, distinctly contrasting, resulting in longitudinal stripes. Tegmina hyaline, translucent, without conspicuous markings, 
pterostigma distinctly dark; venation in distal third dark brown.

Proportions and carination of head and thorax as described for the genus. Metatibiae laterally with 4 small spines. Spinulation of hind legs otherwise as described for the genus.

Male genital complex (figs 29-34).

Genital segment (figs 29, 30) bilaterally asymmetrical: laterodorsal angle of subrectangular process with acute tip on left side, rounded on right side. Anal segment (figs 31, 32) asymmetrical, elongately ovate. Parameres (fig. 33): distal portion produced into a broad lobe, apically rounded. Aedeagus (fig. 34): shaft dorsally with an ear-shaped protrusion near apex (fig. 34, arrow), ventrally with 2 spines: right lateral spine (a1) inserting near shaft base, compressed, taeniform, curved laterad to right side. Left ventral spine (a2) vestigial, tooth-like, inserting mediad of base of right lateral spine. Apical spine of shaft (a5) more or less compressed, bent in a ca. $90^{\circ}$ angle at $1 / 3$ of its length, directed laterad to left side, slightly sinuate; subapical spine of shaft (a6) long, slender, terete, bent at midlength, directed laterobasad to left side. Flagellum in repose not reaching base of shaft, distal flagellum spine (b1) short, stout, directed mediad, and a short, inconspicuous spine (b2) arising from sclerotized ridge at midlength of flagellum (fig. 34, arrow).

Etymology

Named for its type locality, Mt. Aorai, near Papeete, Tahiti.

Distribution

Endemic to Tahiti (Tahiti Nui: Mt. Aorai).

Ecology

On native vegetation including Weinmannia parviflora (Cunoniaceae), Metrosideros collina (Myrtaceae), Myrsine spec. (Myrsinaceae). Between 600-900 m.

\section{Remarks}

Oteana aorai is easily distinguished from all other Oteana species by its light body coloration and the configuration of the aedeagal shaft spines.

Type material

Holotype ơ: Society Islands: Tahiti I., Mt. Aorai Trail, 600 - 900 m, 16.IV. 1999, M. Asche \& H.Hoch, MNHN. 

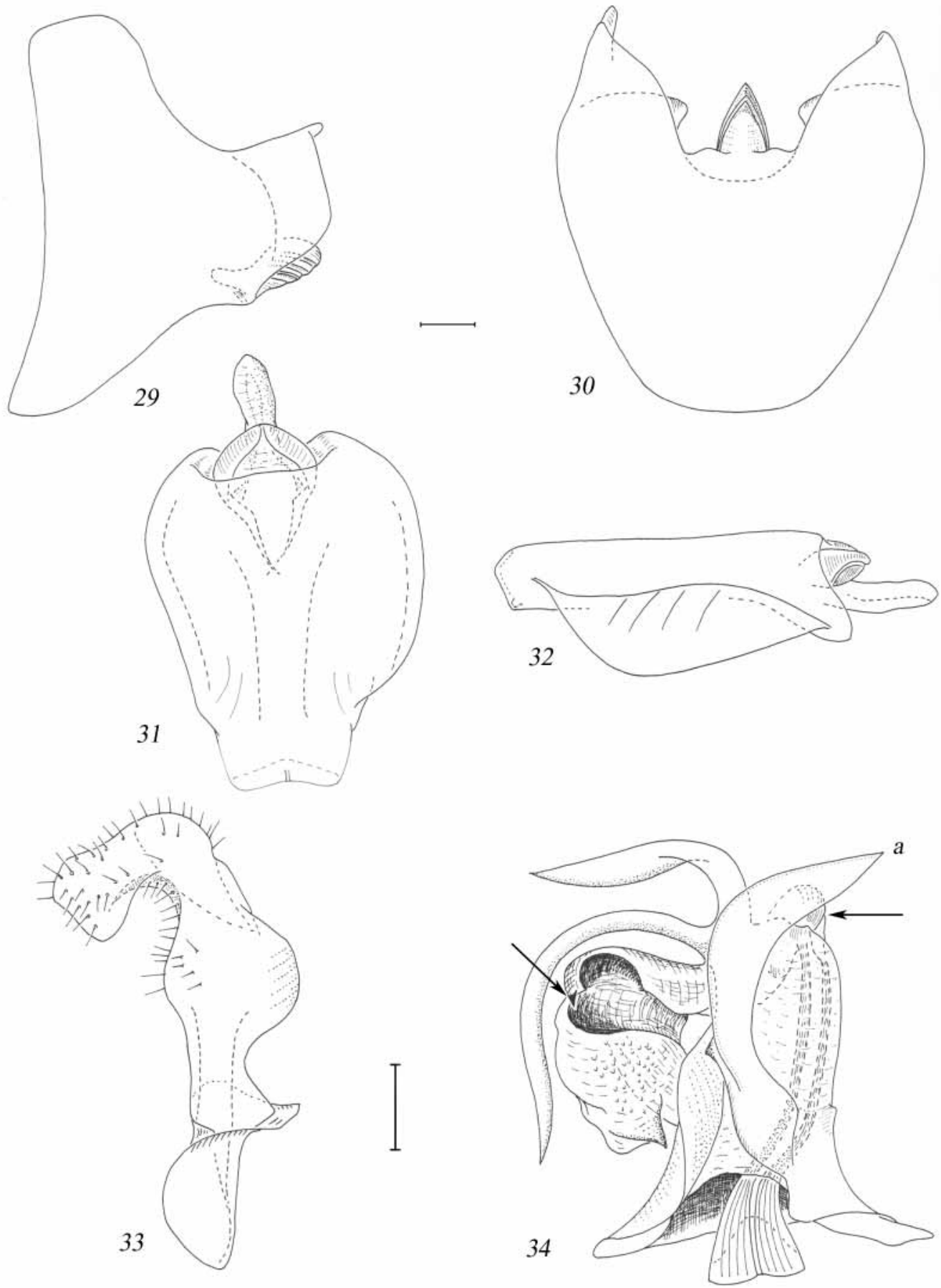

FIGURES 29-34. Oteana aorai sp. nov., holotype. Male genitalia. 29, genital segment, left lateral aspect; 30, same, ventral aspect; 31, anal segment, dorsal aspect; 32, same, left lateral aspect; 33, left paramere, maximal aspect; 34 , aedeagus, ventral aspect. Scale bars equal $0.1 \mathrm{~mm}$. 


\section{Description}

Body length.

Male. 5.0-5.7 $\mathrm{mm}(\mathrm{n}=9)$.

Coloration

Coloration of head generally as in $O$. euphranor, but postclypeus in upper half yellowish-orange, with a dark brown fringe towards frons; postclypeus in lower half and anteclypeus dark brown. Coloration otherwise as described for $O$. euphranor.

Proportions and carination of head and thorax as well as spinulation of hind legs as described for the genus.

Male genital complex (figs 35-40).

Genital segment (figs 35, 36) bilaterally asymmetrical, laterodorsal angle of subrectangular process produced into an acute tip on left side (fig. 35, arrow), rounded on right side. Medioventral process dorsally ridged, in lateral aspect ventral margin distinctly serrate. Anal segment (fig 37, 38) symmetrical, ovate. Parameres (figs. 39) with distal portion in lateral aspect apically rounded, dorsal margin serrate, with an acute tip directed mediad (fig. 39 a, b, arrow). Aedeagus (figs 7, 40): shaft dorsally with a small, inconspicuous, ear-shaped protrusion, ventrally with 4 spines: right lateral spine (a1) arising from joint base with right median spine (a2). Right lateral spine long, terete, slender throughout, curved laterad to right side; median right spine short, erect. Median left spine (a3) and left lateral spine (a4) also arising from a common base: median left spine stout, rapidly tapering, erect; left lateral spine slender, filiform, directed mediad towards tip of median left spine. Apcial spine of shaft (a5) long, terete, with a distinct "knee" near its base (fig. 40, arrow), curved semicircularly laterobasad to the left side. Subapical spine (a6) ca. 1/3 the length of apical spine, slender and terete at base, distally compressed and broadened, sinuate, bent laterad to the left side, tip pointing apically. Flagellum in repose not reaching base of shaft; distal flagellum spine (b1) directed mediad. Sclerotized flagellum ridge produced into a sharp edge at midlength of flagellum.

Etymology

Named for a refuge hut on the Mt. Aorai trail, Fare Mato.

Distribution

Endemic to Tahiti (Tahiti Nui and Tahiti Iti).

Ecology

On native vegetation including Weinmannia parviflora (Cunoniaceae), Metrosideros collina (Myrtaceae), Myrsine spec. (Myrsinaceae). Between 900 to $1400 \mathrm{~m}$. 

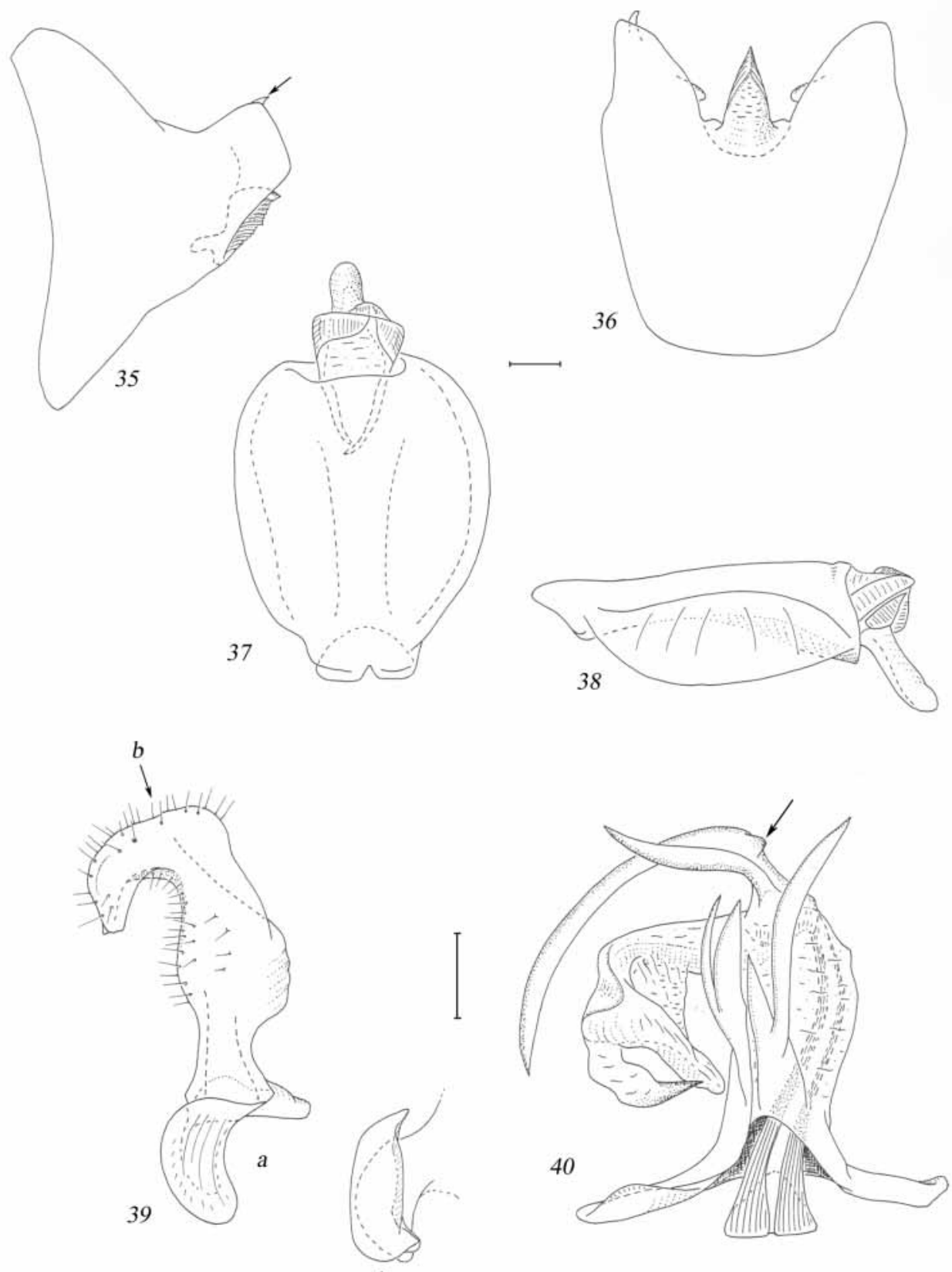

FIGURES 35-40. Oteana mato sp. nov., holotype. Male genitalia. 35, genital segment, left lateral aspect; 36, same, ventral aspect; 37, anal segment, dorsal aspect; 38, same, left lateral aspect; 39, left paramere: a, maximal aspect, b, caudal aspect; 40, aedeagus, ventral aspect. Scale bars equal $0.1 \mathrm{~mm}$.

\section{Remarks}

Oteana mato differs from all other Oteana species by the coloration of the postclypeus (upper half yellowish-orange) and particularly by the configuration of the ventral, apical, and subapical aedeagus shaft spines. 
Type material.

Holotype $\diamond^{x}$, Society Is.: Tahiti I., Taiarapu: above Vaiufaufa [Tahiti Iti], 900 m, 3.VII. 1977, S.L. Montgomery, at light, BPBM (type nr 16621).

Paratypes. Tahiti Iti. $3 \sigma^{x}$, same data as holotype; $2 \sigma^{x}$, same data as holotype, except

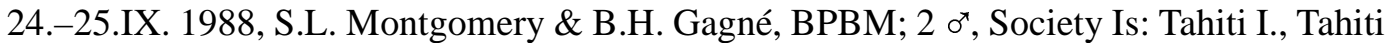
Iti, Metrosideros collina (glabrous), D. M. Percy, BPBM. Tahiti Nui. $3 \sigma^{\star}$, Society Is: Tahiti I., Mt Aorai Trail, 900 - 1400 m, 16.IV.1999, M.Asche \& H. Hoch, MNHN, AH.

\section{Oteana ata sp. nov.}

(figs 41-46)

Description.

Body length.

Male. 5.3 - $5.4 \mathrm{~mm}(\mathrm{n}=3)$.

Coloration as described for $O$. euphranor as well as proportions and carination of head and thorax. Metatibiae laterally with 1-2 small spines (variable within individuals), spinulation of hind legs otherwise as described for the genus.

Male genital complex (figs 41-46).

Genital segment (figs 41, 42) nearly bilaterally symmetrical: laterodorsal angle of subrectangular lobes rounded on both sides; subrectangular process on right side slightly more pronounced than on left side. Anal segment (figs 43, 44) symmetrical, elongately ovate. Parameres (fig. 45) with distal part produced into a stout acute tip directed mediad. Aedeagus (fig. 46): shaft ventrally with 2-3 spines: in specimens with 3 ventral shaft spines: median spine (a2+a3?) more or less strongly developed, apically medially truncate, slightly incised; right lateral (a1) and left lateral spine (a4) feebly developed. In specimens with 2 ventral shaft spines, left spine strongly developed, apically acute, right spine feebly developed, as long as left spine. Apical spine of shaft (a5) long, terete, slender throughout, bent in a ca. $90^{\circ}$ angle at midlength, in repose directed laterobasad to left side. Subapical spine of shaft (a6) slender at base, nearly straight directed laterodorsad to left side. Flagellum in repose not reaching base of shaft, distal flagellum spine (b1) strongly pronounced, directed straight basad. Sclerotized flagellum ridge produced into a strong, stout spine (b2) directed laterobasad to the left side.

Etymology

Named for a refuge hut, Fare Ata, near the summit of Mt. Aorai, Tahiti.

Distribution

Endemic to Tahiti (Tahiti Nui). 

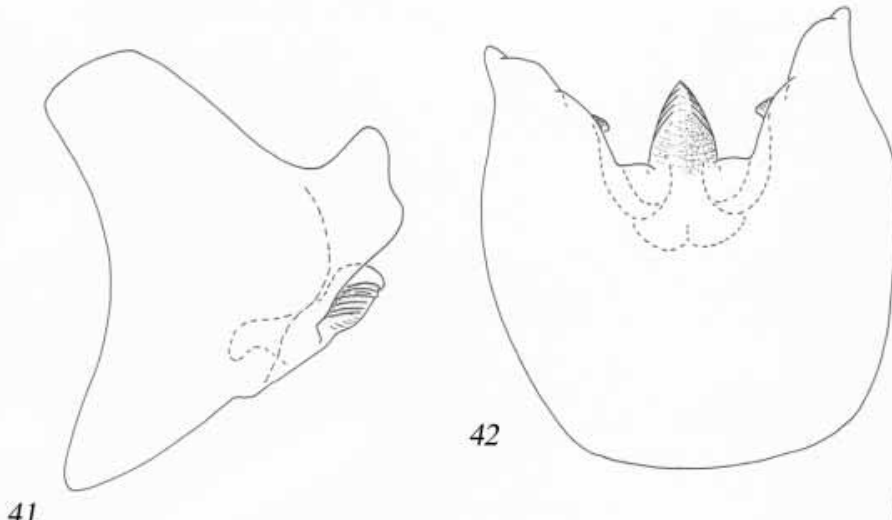

41

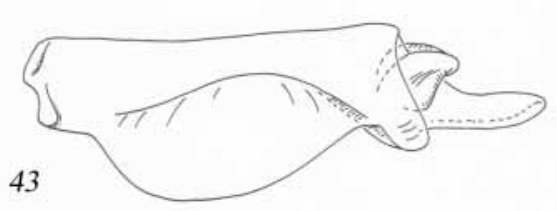

44

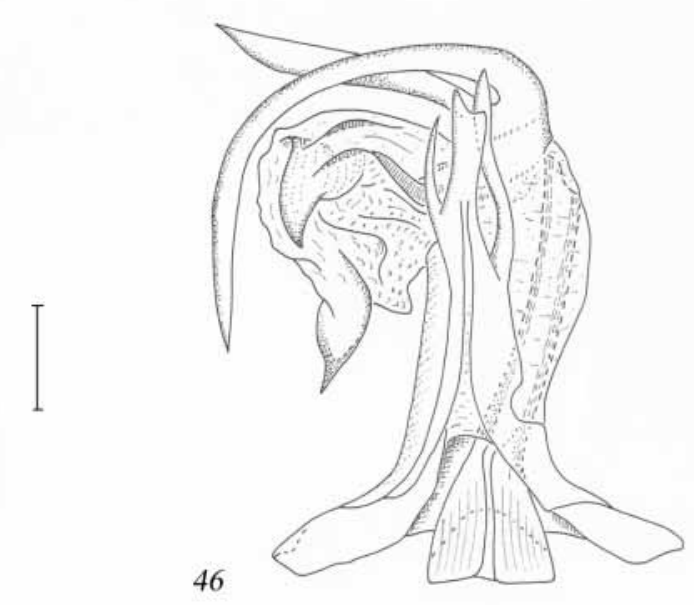

FIGURES 41-46. Oteana ata sp. nov., holotype. Male genitalia. 41, genital segment, left lateral aspect; 42, same, ventral aspect; 43, anal segment, left lateral aspect; 44, same, dorsal aspect; 45, paramere, maximal aspect; 46, aedeagus, ventral aspect. Scale bars equal $0.1 \mathrm{~mm}$.

Ecology

On native vegetation including Weinmannia parviflora (Cunoniaceae), Metrosideros collina (Myrtaceae), Myrsine spec. (Myrsinaceae); 900 to above $1400 \mathrm{~m}$.

\section{Remarks}

Oteana ata differs from all other Oteana species by the configuration of the ventral aedeagal spines. 
Type material

Holotypus ơ, Society Is: Tahiti I., Mt. Aorai Trail, 900 - 1400 m, 16.IV. 1999, M. Asche \& H. Hoch, MNHN. Paratypes: $2 \sigma^{x}$, same data as holotype, except above 1400m, MNHN, AH.

\section{Oteana moana sp. nov.}

(figs 47-53)

\section{Description}

Body length.

Male 6.0-6.4 mm ( $\mathrm{n}=5)$

Coloration.

Vertex dark brown except posterior angles pale yellow. Frons sordid light brown to dark brown, in some individuals with a yellowish mark at lateral corners of frontoclypeal suture; carination yellow. Post- and anteclypeus dark brown; in some individuals medially with a circular yellow-brown mark below frontoclypeal suture. Pronotum with discoidal and ventral areas dark brown; carinae of pronotum and posterior margin whitish. Mesonotum dark brown, carinae yellow-orange, in some individuals the area enclosed by lateral carinae on each side chestnut-brown to honey-yellow, posterior tip of mesonotum pale yellow. Tegmina hyaline, Y-vein brown at base, close to anterior margin suffusely brown. Angle between claval veins and commissural margin brown. Pterostigma brown, crossveins distad of nodal line overlayed with a brown suffusion. Wings hyaline, veins brown. Legs brown, distal end of femura and tibiae slightly lighter.

Head and thorax

Variation is observed between the populations from Mt. Aorai (Tahiti Nui), and Vaiufaufa (Tahiti Iti).

Proportions of head and thorax as described for the genus, in the specimen from Vaiufaufa the vertex is slightly longer and narrower than in specimens from Mt. Aorai. Venation of tegmina, especially distad of nodal line variable due to different degrees of (slight) reduction in length: the veinlets reach the posterior margin either branched or unbranched. Spinulation of hind legs as described for the genus. 

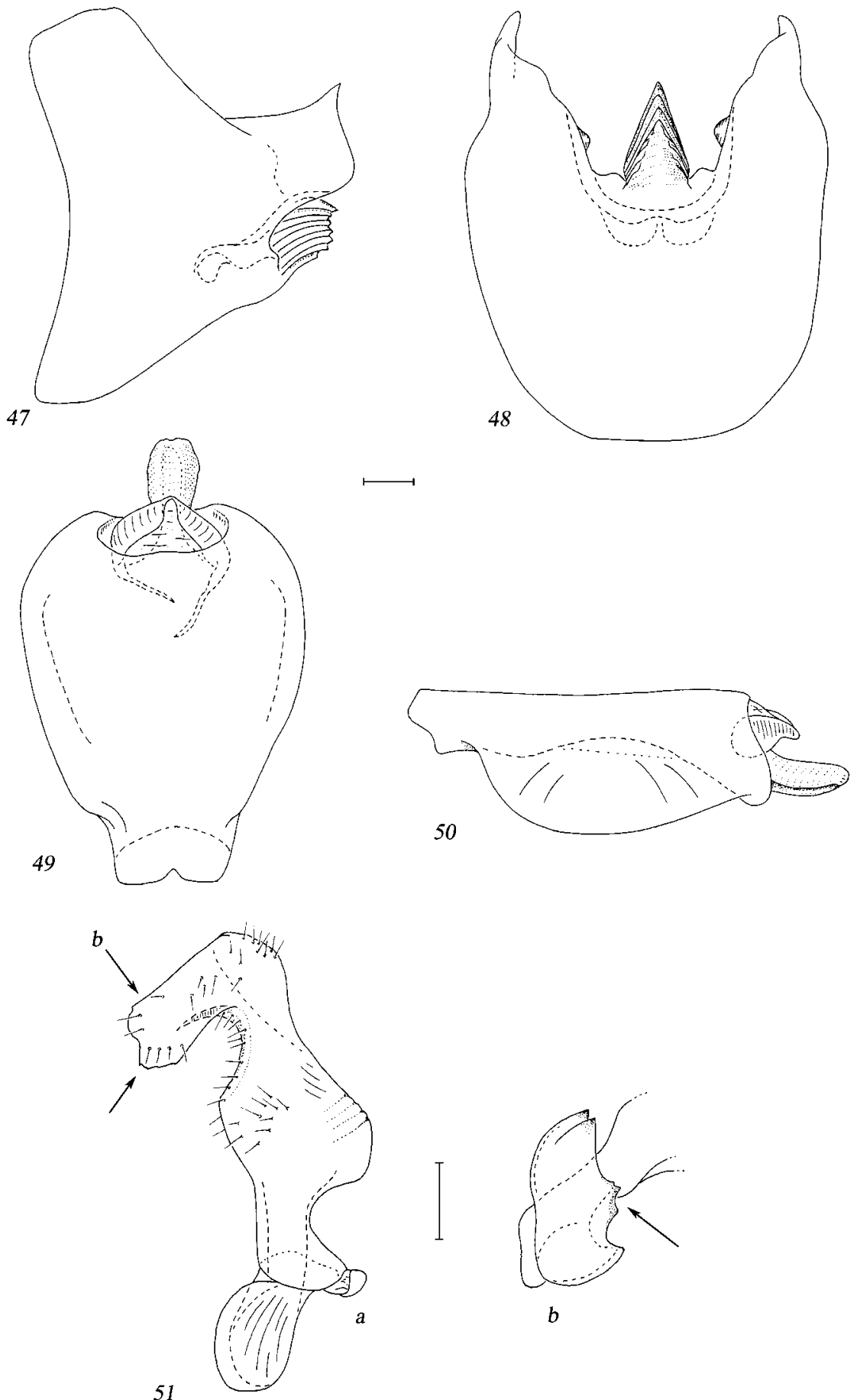

$b$

FIGURES 47-51. Oteana moana sp. nov. Male genitalia. 47, genital segment, left lateral aspect; 48, same, ventral aspect; 49, anal segment, dorsal aspect; 50, same, left lateral aspect; 51, left paramere, maximal aspect; b: caudal aspect. Scale bars equal $0.1 \mathrm{~mm}$. 

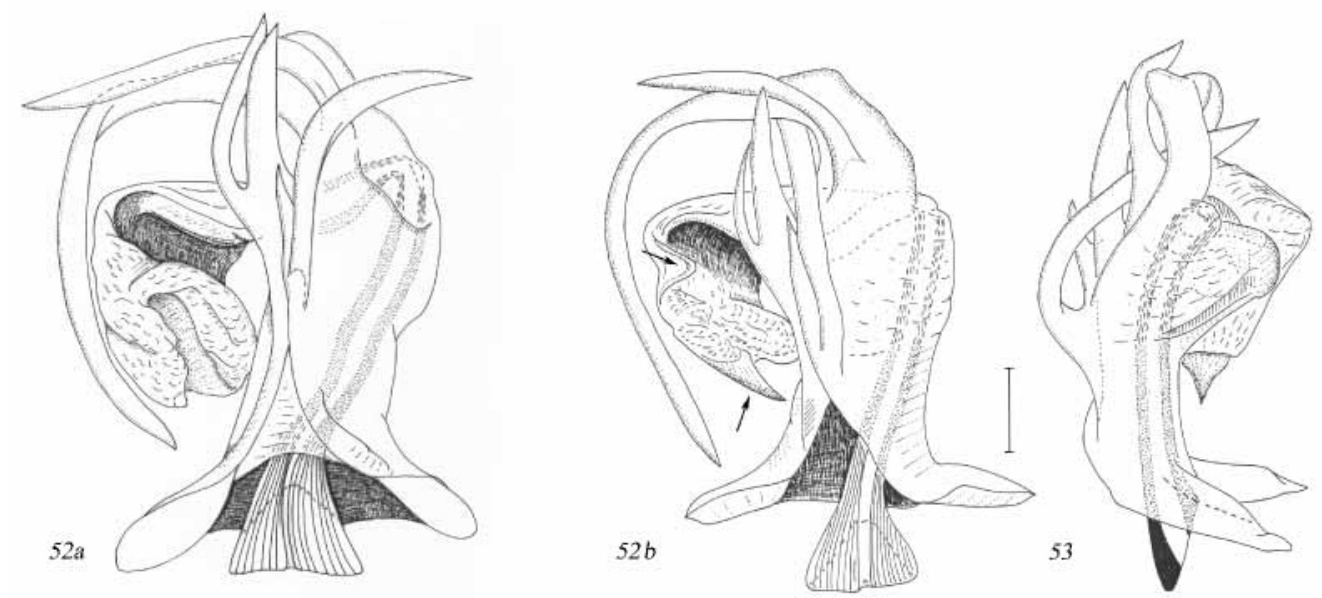

FIGURES 52-53. Oteana moana sp. nov. Male genitalia. 52, aedeagus, ventral aspect: a, male from Mt. Aorai (holotype); b, male from Vaiufaufa (paratype); 53, same, right lateral aspect, male from Vaiufaufa. Scale bar equals $0.1 \mathrm{~mm}$.

Male genital complex (figs 47-53).

Genital segment (figs 47, 48) bilaterally asymmetrical, laterodorsal angle of subrectangular process produced into an acute tip on left side, rounded on right side; medioventral process dorsally ridged. Anal segment (figs 49, 50) slightly asymmetrical, elongately ovate. Parameres with distal portion apically produced into an acute tip directed mediad, median margin dentate (fig. 51, arrow). Aedeagus (figs 52, 53): shaft ventrally with 4 spines: right lateral spine (a1) long, slender, terete, curved dorsad (fig. 52a) (in the specimen from Vaiufaufa passing to the dorsal side underneath apical and subapical shaft spines: figs 52b, 53); median right spine (a2) short, slender, erect; median left spine (a3) and left lateral spine (a4) arising from a common base; median left spine conical, erect, rapidly tapering; left lateral spine more feebly developed, slender throughout, gradually curved mediad. Apical spine of shaft (a5) arising from a solid base, long, slender, terete, bent at a ca. $90^{\circ}$ angle at midlength, curved laterobasad to left side. Subapical spine of shaft (a6) arising from a narrow base, slender, terete, ca. half the length of apical spine, directed laterad to left side. Flagellum in repose not reaching base of shaft; distal flagellum spine (b1) inconspicuous or absent (in specimens from Mt. Aorai) or distinct (specimen from Vaiufaufa); flagellum at midlength with a distinct sclerotized ridge in the specimen from Vaiufaufa, this not as strongly expressed in the specimens from Mt. Aorai.

Etymology

"Moana" is the Polynesian word for Pacific Ocean. 
Distribution

Endemic to Tahiti (Tahiti Nui and Tahiti Iti).

Ecology

On native vegetation including Weinmannia parviflora (Cunoniaceae), Metrosideros collina (Myrtaceae), Myrsine spec. (Myrsinaceae); 900-1650 m.

Remarks

In the configuration of the aedeagal spinulation, $O$. moana is most similar to $O$. euphranor but can be distinguished from this species by its larger body size as well as by its asymmetrical genital segment, details of the aedeagus' ventral shaft spines and a relatively longer apical shaft spine.

There is some variation observed between the specimens from Mt. Aorai and the (single) specimen from Vaiufaufa. In the latter, the vertex is slightly longer and narrower than in the males from Mt. Aorai, and the coloration is generally lighter, especially so that of the frons and postclypeus which is honey-yellow to light brown vs dark brown in the specimens from Mt. Aorai. Pertaining to the male genital complex, it displays the same arrangement of aedeagal shaft spines; however, the right lateral ventral shaft spine is bent dorsally underneath the apical and subapical spines (figs $52 \mathrm{~b}, 53$ ). Also, the flagellum bears a distinct distal flagellum spine which is much less developed or even missing in the males from Mt. Aorai. Whether this variability is merely intraspecific or may be an indication of interrupted gene-flow between the two populations cannot be decided on the basis of the existing material.

Type material

Holotype $0^{x}$, Society Is: Tahiti I., Mt. Aorai Trail [Tahiti Nui], $1400-1650$ m, 12.V.1999, M. Asche, MNHN.

Paratypes. Tahiti Nui. $10^{x}$, same data as holotype; $20^{x}$, same data as holotype except $900-1400$ m, 16.IV.1999, M. Asche \& H. Hoch, AH. Tahiti Iti. $1 \sigma^{\star}$, Society Is: Tahiti I., Taiarapu, above Vaiufaufa, 900 m, 24. - 25. IX. 1977, S.L. Montgomery, BPBM.

\section{Oteana pouvana sp. nov.}

(figs 54-59)

Description

Body length.

Male. 6.2-6.6 mm $(\mathrm{n}=3)$.

Coloration.

Coloration of head as described for O. euphranor, except for the postclypeus which is yellowish in $O$. pouvana. Pro- and mesonotum as in $O$. euphranor. Tegmina with venation 
stramineous in proximal two-thirds, dark brown in distal third. Costal vein and pterostigma dark brown.

Spinulation of hind legs as described for the genus, with some variation observed: one specimen displayed 4 and 2 spines, respectively, laterally on the hind tibia.

Male genital complex (54-59).

Genital segment (figs 54, 55) bilaterally slightly asymmetrical: dorsolateral angle of subrectangular lobe acute on left side, rounded on right side. Anal segment (figs 56, 57) bilaterally symmetrical, broadly ovate. Parameres (fig. 58) distally produced into a blunt angle directed mediad, mediodorsal margin serrate. Aedeagus (fig. 59): shaft with 3 ventral spines: right lateral spine (a1) inserting near base of shaft, compressed, taeniform, widest at midlength, rapidly tapering, dorsolateral margin irregularly sinuate, twisted at base, curved laterad to right side. Median spine (a2) inserting near base, short, thorn-like; left lateral spine (a3) inserting with a wide base, compressed, taeniform, curved laterad to right side, more or less parallel to right lateral spine. Apical spine of shaft (a5) very long, compressed, taeniform, bent at ca. 1/5 of its total length in a nearly right angle, in repose directed laterad to the left side. Subapical spine of shaft (a6) arising from a narrow base, ca. half as long as apical spine of shaft, but of similar shape and direction. Flagellum in repose not reaching base of shaft, distal flagellum spine (b1) present, not strongly sclerotized, in repose directed straight mediad. Sclerotized ridge of flagellum with ventromedian margin irregularly serrate.

Etymology

Named in honor of Pouvanaa a Oopa, proponent of Polynesian autonomy and first Polynesian to win a seat in the French Chamber of Deputies, in 1949.

Distribution

Endemic to Tahiti (Tahiti Nui).

Ecology

On native vegetation including Weinmannia parviflora (Cunoniaceae), Metrosideros collina (Myrtaceae), Myrsine spec. (Myrsinaceae); 600-1400 m.

Remarks

Oteana pouvana resembles $O$. iaorana in the aedeagus spine configuration, but differs from this species by the long and taeniform apical shaft spine, as well as in the distal flagellum spine, which is much more strongly pronounced in $O$. iarorana.

Type material

Holotype ơ, Society Is: Tahiti I., Mt. Aorai Trail, ca. 600 - 1200 m, 14.IV.1999, M. Asche \& H. Hoch, MNHN.

Paratypes: $1 \sigma^{x}$, same data as holotype, AH; $1 \circ^{x}$, same data as holotype except 1000 1400 m, 12.V.1999, M. Asche, AH. 


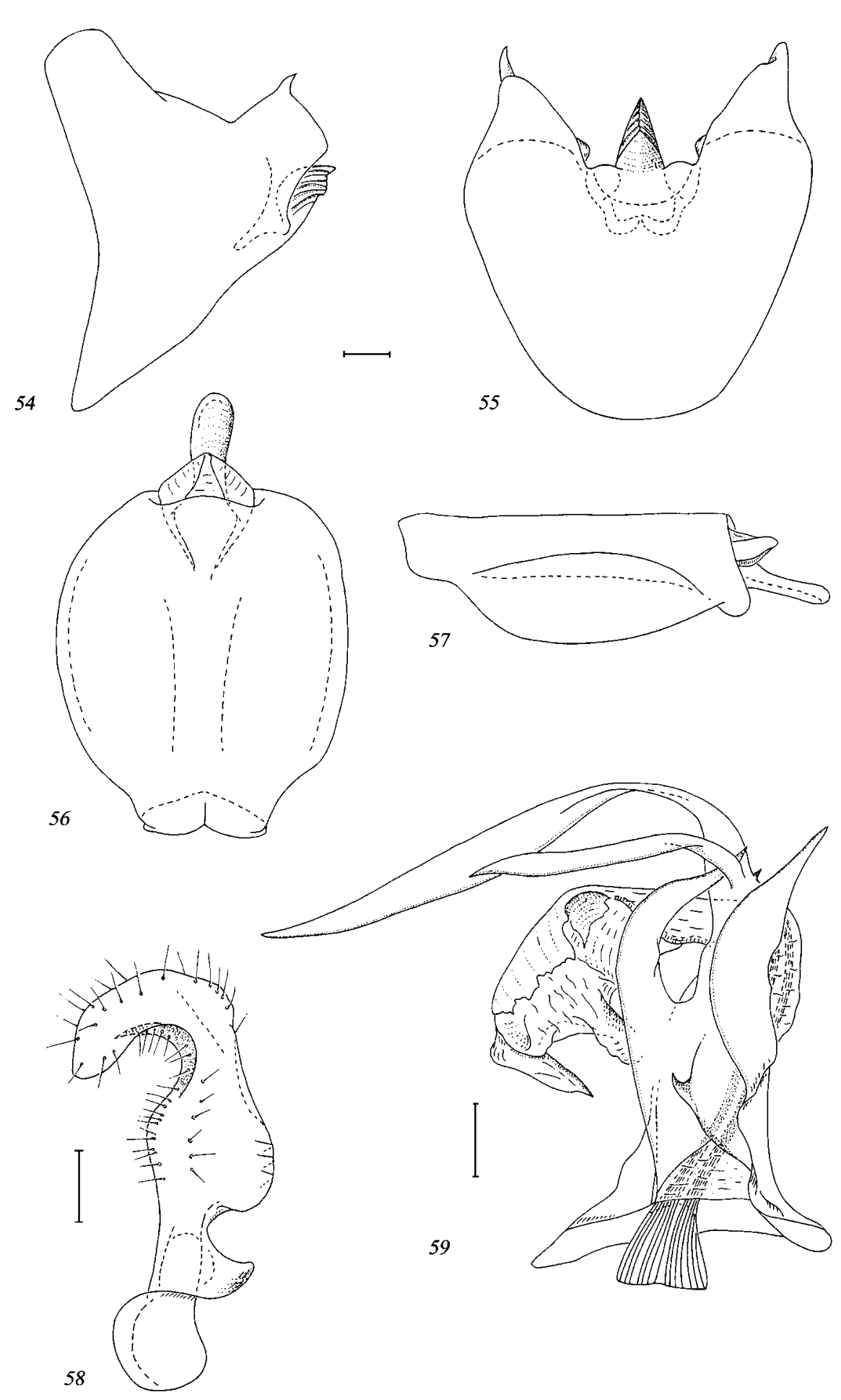

FIGURES 54-59. Oteana pouvana sp. nov., holotype. Male genitalia. 54, genital segment, left lateral aspect; 55, same, ventral aspect; 56, anal segment, dorsal aspect; 57, same, left lateral aspect; 58, left paramere, maximal aspect; 59, aedeagus, ventral aspect. Scale bars equal $0.1 \mathrm{~mm}$. 
Oliarus eurynome Fennah 1958: 132

Supplementary description.

Body length.

Male. 5.0-5.2 mm (n=2). Female unknown.

Coloration.

Anterior part of vertex and areolets dark brown, anterior corners of vertex stramineous. Frons testaceous, with dark brown irregular band above frontoclypeal suture. Postclypeus testaceous, anteclypeus dark brown. Carinae of head yellowish. Pronotum with discoidal and ventral areas dark brown, carinae stramineous. Tegulae stramineous. Mesonotum with distinct longitudinal stripes: median stripe dark brown, median carina yellowish, flanked on each side by a yellowish stripe (consisting of lateral carinae and areas enclosed by them), lateral portion of mesonotum testaceous, posterior tip stramineous. Tegmina and wings hyaline, translucent, without any conspicuous pattern. Venation of tegmina yellowish brown, darkening towards distal third, costal vein and pterostigma dark brown. Body dark brown, legs testaceous.

Proportions and carination of head and thorax as well as spinulation of hind legs as described for the genus.

Metatibiae laterally with 1 spine, otherwise as described for the genus.

Male genital complex (figs 60-65)

Genital segment (figs 60,61) bilaterally slightly asymmetrical, dorsal apical angle of subrectangular lobe slightly more pronounced on right side, rounded; medioventral process sharply ridged posteriorly. Anal segment (figs 62, 63) in dorsal aspect more or less bilaterally symmetrical, broadly ovate. Parameres (fig. 64) in strict lateral aspect distally produced into a rounded lobe directed basad, dorsocaudal margin dentate, tip pointed, directed mediad. Aedeagus (fig. 65): shaft ventrally with 3 spines: right lateral spine (a1) slender, S-shaped, slightly dilated subapically, curved to the right side; median (a3) and left lateral spine (a4) arising from a common base. Median spine variable in shape: compressed, either distally pointed (as in the holotype, fig. 65b, arrow) or apically incised, bifurcate (as in the paratype, fig. 65a, arrow). Left lateral spine (a4) terete, strong, curved gradually to right side. Apical spine of shaft (a5) arising from a wide base, slender throughout, curved laterobasad. Subapical spine of shaft (a6) slender at base, broadening subapically, directed laterad to left side. Flagellum with 2 spinose processes: distal flagellum spine (b1) slender, acute, arising from a strongly sclerotized lateroventral ridge, directed mediad, and a strong, compressed spine arising from ventral flagellum base, curved (latero-) basad. 


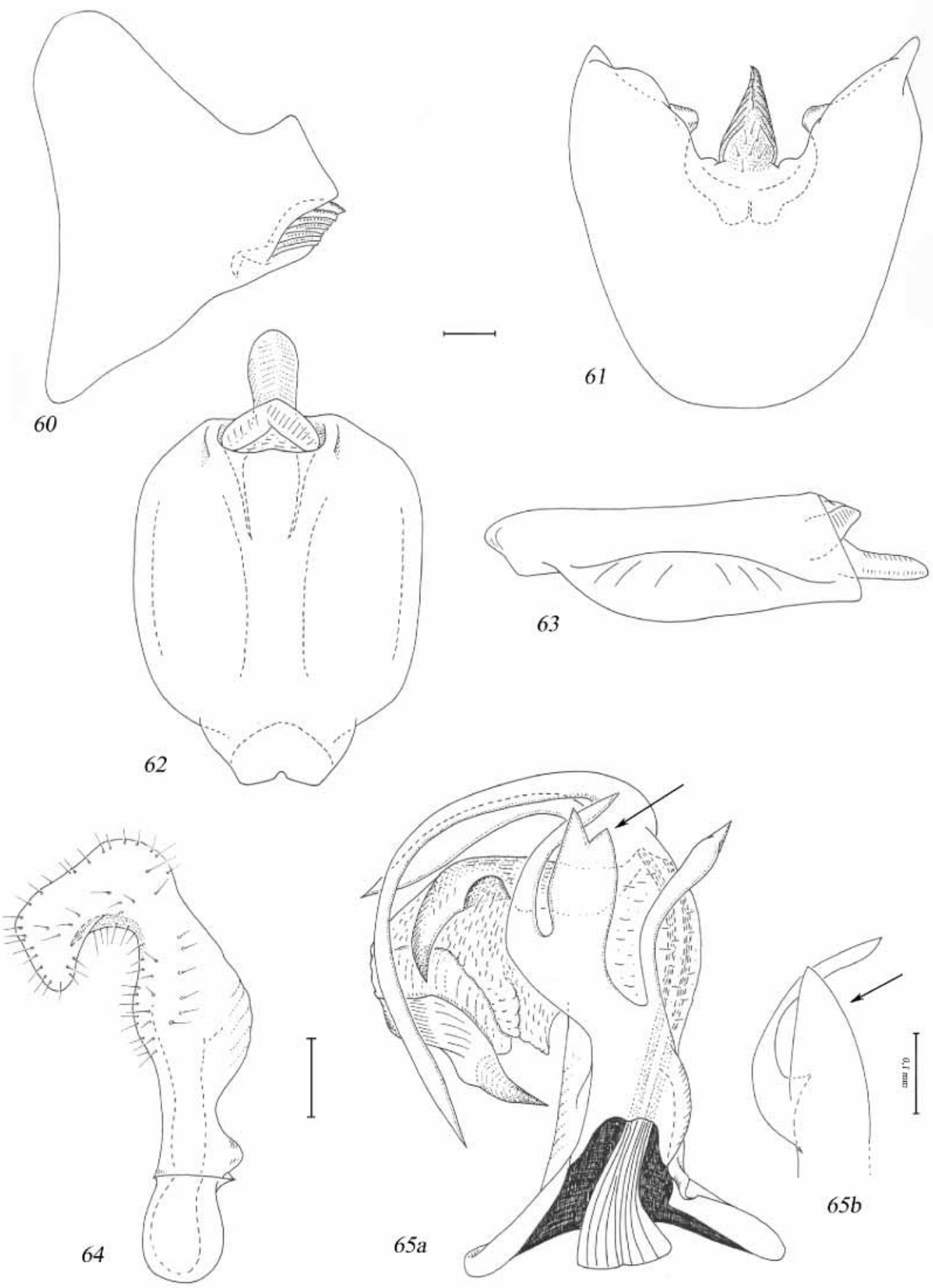

FIGURES 60-65. Oteana eurynome (Fennah 1958). Figs 60-65 a: paratype; fig. 65 b: holotype. Male genitalia. 60, genital segment, left lateral aspect; 61, same, ventral aspect; 62, anal segment, dorsal aspect; 63, same, left lateral aspect; 64, left paramere, maximal aspect; 65, a: aedeagus, ventral aspect, b: variation of median ventral spine. Scale bars equal $0.1 \mathrm{~mm}$. 
Distribution

Endemic to Moorea.

Ecology

Unknown.

Remarks

Oteana eurynome differs from all other Oteana species by the presence of only one lateral metatibial spine, and by the configuration of the aedeagus spines.

Material examined

Holotype $\sigma^{x}$ : Society Islands: Moorea I., N. ridge Mt. Teaharua, 1500-2000ft, 25.IX.1934, E.C. Zimmerman, BPBM (type nr 2629). Paratype ơ: same data as holotype, BPBM.

Oteana aimeho sp. nov.

(figs 66-72)

Description

Body length.

Male. 4.8 - $5.3 \mathrm{~mm}(\mathrm{n}=4)$. Female. $5.9-6.0 \mathrm{~mm}(\mathrm{n}=4)$.

Coloration sexually dimorphic:

Male. Median part of vertex and areolets dark brown, posterior corners of vertex whitish. Frons and clypeus dark brown. Carinae of head whitish. Frons with white spot laterally on ascending portion of frontoclypeal suture. Pronotum with discoidal and ventral areas dark brown; carinae whitish. Tegulae whitish. Mesonotum inconspicuously striped longitudinally: laterally dark brown, medially testaceous, carinae yellowish. Tip of mesonotum whitish. Body and legs brownish, metatibiae with a longitudinal whitish stripe, $2^{\text {nd }}$ and $3^{\text {rd }}$ metatarsal segments whitish. Tegmina and wings hyaline, translucent; pterostigma and venation of tegmina light brown, slightly darkening towards distal third, costal vein medially (at clavus junction) distinctly darker.

Female.

Vividly coloured. Anterior part of vertex and areolets dark brown, posterior corners of vertex white. Frons yellowish brown, darker at apex and above frontoclypeal suture. Median carina of frons and clypeus yellowish, lateral carinae white, frons laterally of ascending portion of frontoclypeal suture white. Postclypeus apically yellowish, darkening towards anteclypeus, anteclypeus dark brown. Pronotum with discoidal and ventral areas dark brown, carinae whitish. Tegulae yellowish. Mesonotum yellowish. Tegmina translucent, venation light brown, darker in distal third, with dark bands along transverse 
veinlets. Abdominal tergites distinctly striped horizontally: dark brown anteriorly, yellowish brown medially, and yellow posteriorly. Legs yellowish.

Proportions and carination of head and thorax as well as spinulation of hind legs as described for the genus, with slight variation pertaining to the lateral metatibial spines: 3 in males, $2-3$ in females.
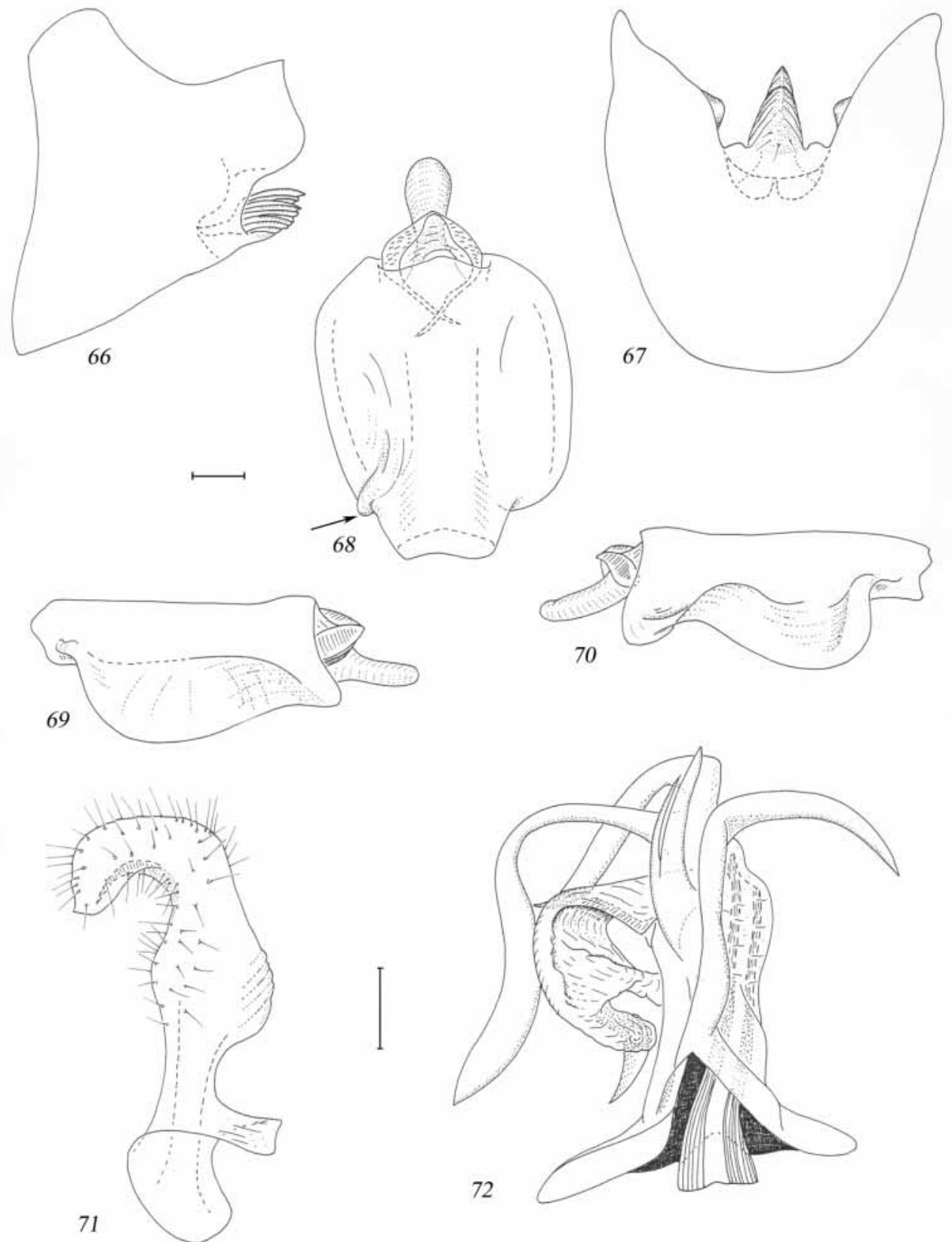

FIGURES 66-72. Oteana aimeho sp. nov., paratype. Male genitalia. 66, genital segment, left lateral aspect; 67, same, ventral aspect; 68, anal segment, dorsal aspect; 69, same, left lateral aspect; 70, same, right lateral aspect; 71, left paramere, maximal aspect; 72, aedeagus, ventral aspect. Scale bars equal $0.1 \mathrm{~mm}$. 
Male genital complex ( figs 66-72).

Genital segment (figs 66, 67) bilaterally slightly asymmetrical: dorsal apical angle of subrectangular lobe acute on left side, rounded on right side; medioventral process in lateral aspect with distal margin serrate. Anal segment (figs 68-70) in dorsal aspect distinctly asymmetrical, right laterally at base produced into a conspicuous ear-shaped lobe (fig. 68, arrow, fig.70). Parameres (fig. 71) distally produced into a pointed tip directed mediad; mediodorsal margin serrate. Aedeagus (fig. 72): shaft dorsally with an ear-shaped protrusion, ventrally with 3 spines: right lateral spine (a1) arising medially near base, long slender, abruptly bent laterad to the right side at ca. $1 / 2$ its length; median spine (a3) and left lateral spine (a4) inserting with a common base at midlength of shaft; median spine strong, directed apically; left lateral spine more feebly developed, slender, slightly shorter than median spine. Apical spine of shaft (a5) strongly developed, abruptly bent near base, directed dorsolaterad; subapical spine of shaft (a6) long, slender at base, directed straight laterad in proximal half of its total length, then rectangularly bent basolaterad to left side, subapically dilated. Flagellum with distal flagellum spine (b1) well-developed, directed basad.

Female genitalia as described for the genus.

Etymology

Aimeho is an ancient Polynesian name for Moorea.

Distribution

Endemic to Moorea.

Ecology

On native vegetation: Metrosideros collina (Myrtaceae) and Weinmannia parviflora (Cunoniaceae); in medium elevations (300-830 m).

Remarks

Oteana aimeho differs from $O$. eurynome by the presence of 2-3 lateral metatibial spines (instead of one in O. eurynome), and from this and all other Oteana species by the aedeagal spine configuration and the distinctly asymmetrical anal segment.

Type material

Holotype ơ: Society Islands: Moorea, Mt. Rotui, btw. 300-450 m, 3.VI.2002, ex Metrosideros collina, Weinmannia parviflora, D. M. Percy, BPBM (type nr. 16618). Paratypes: 2 ㅇ, same data as holotype; $5 \sigma^{\star}, 3$ ㅇ, Moorea, Mt. Mouaputa summit, 730-830 m, “399”, ex Metrosideros collina, 05.VI.2002, D.M. Percy, BPBM. 
Oteana omai sp. nov.

(figs 73-78)

Description

Body length. Male. $7.5 \mathrm{~mm}, \mathrm{n}=1$. Female. $8.7 \mathrm{~mm}(\mathrm{n}=1)$.

\section{Coloration}

Anterior part of vertex and areolets dark brown, posterior corners of vertex stramineous. Frons irregularly testaceous, darkening towards frontoclypeal suture. Postclypeus testaceous, darkening towards anteclypeus; anteclypeus dark brown. Carinae of head yellowish. Pronotum with discoidal and ventral areas dark brown, carinae stramineous. Tegulae stramineous in dorsal aspect, slightly darker ventrally. Mesonotum in male with median portion (=area between carinae) light brown, carinae yellowish, lateral portions dark brown; without conspicuous longitudinal stripes. In female, mesonotum with areas between lateral carinae on each side lighter, yellowish, thus the mesonotum appears more distinctly longitudinally striped. Body and legs testaceous. Tegmen and wings hyaline, translucent, without any conspicuous pattern. Pterostigma distinct, light brown. Venation of tegmina yellowish brown, Y-vein and transversal veinlets slightly darker.

Proportions and carination of head and thorax as described for the genus; metatibiae laterally with 2-3 spines, otherwise as described for the genus.

Male genital complex (figs 73-78).

Genital segment (figs 73, 74) bilaterally asymmetrical, dorsal apical angle of subrectangular lobe on left side more strongly pronounced than on right side (fig. 74, arrow); subrectangular lobe in lateral aspect with a distinct ventral corner. Anal segment (figs 75,76 ) bilaterally symmetrical, broadly ovate. Parameres (fig. 77) distally produced into a pointed tip, mediodorsal margin serrate. Aedeagus (fig. 78): shaft with 3 ventral spines (a1-a3) and a distinctly developed longitudinal ridge (a4?). Right lateral spine (a1) compressed, slender, curved laterad to the right side; median spines (a2, a3) short, toothlike. Apical spine of shaft (a5) long, terete, slender, curved laterobasad; subapical spine of shaft (a6) comparatively thin, curved more or less straight laterad to left side. Flagellum in repose not reaching base of shaft, distally bispinose..

Female genitalia as described for the genus.

Etymology

Named in the memory of Omai, a man from Huahine and one of the first Polynesians to visit Europe, travelling to England on board the HMS "Adventure" with Capt. Furneaux, a contemporary of Capt. Cook.

Distribution

Endemic to Huahine. 
Unknown.

\section{Remarks}

This species closely ressembles Oteana temehani sp.nov. (described below). See diagnostic remarks under $O$. temehani.
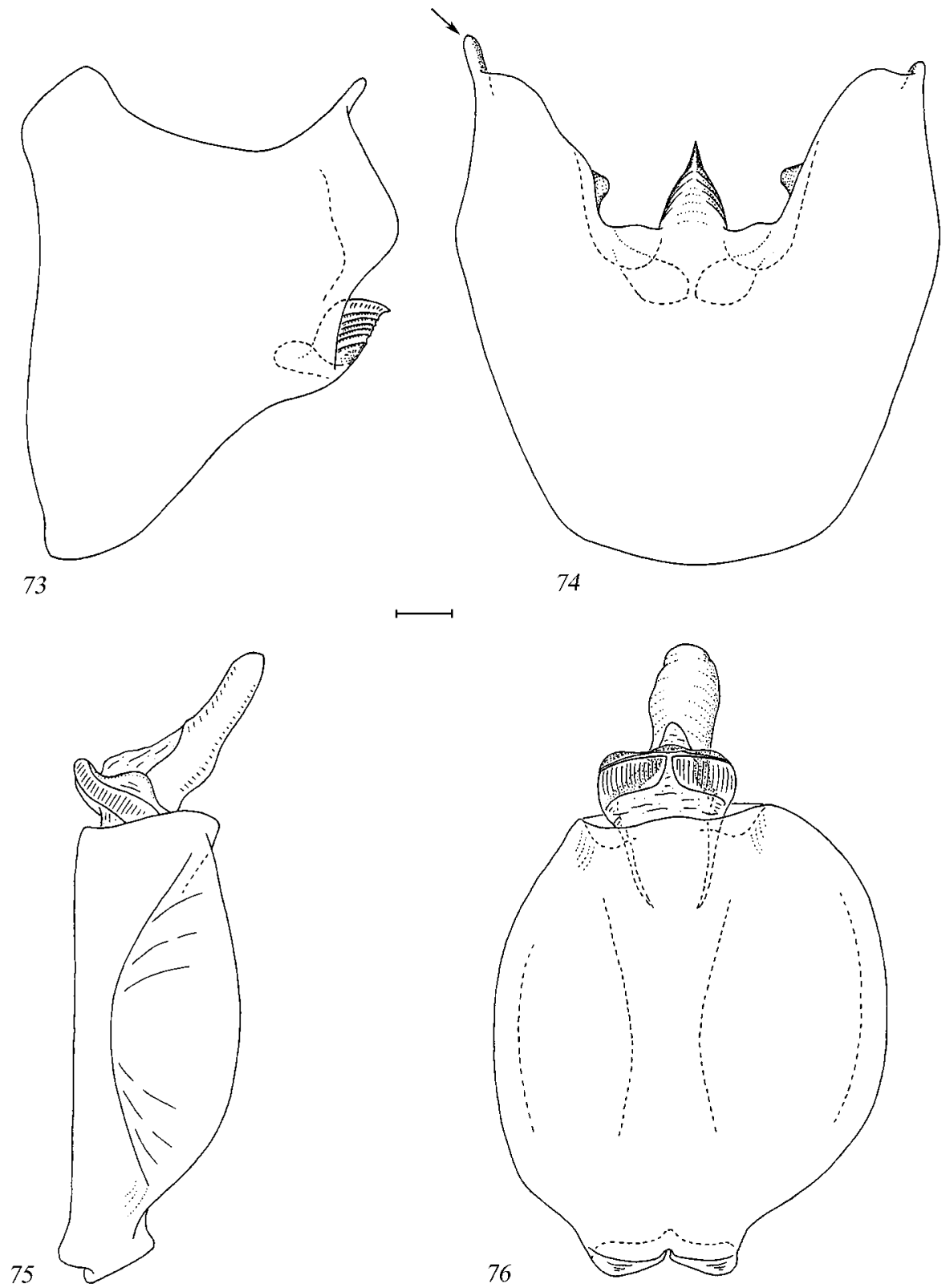

FIGURES 73-76. Oteana omai sp. nov., holotype. Male genitalia. 73, genital segment, left lateral aspect; 74, same, ventral aspect; 75, anal segment, left lateral aspect; 76, same, dorsal aspect. Scale bar equals $0.1 \mathrm{~mm}$. 

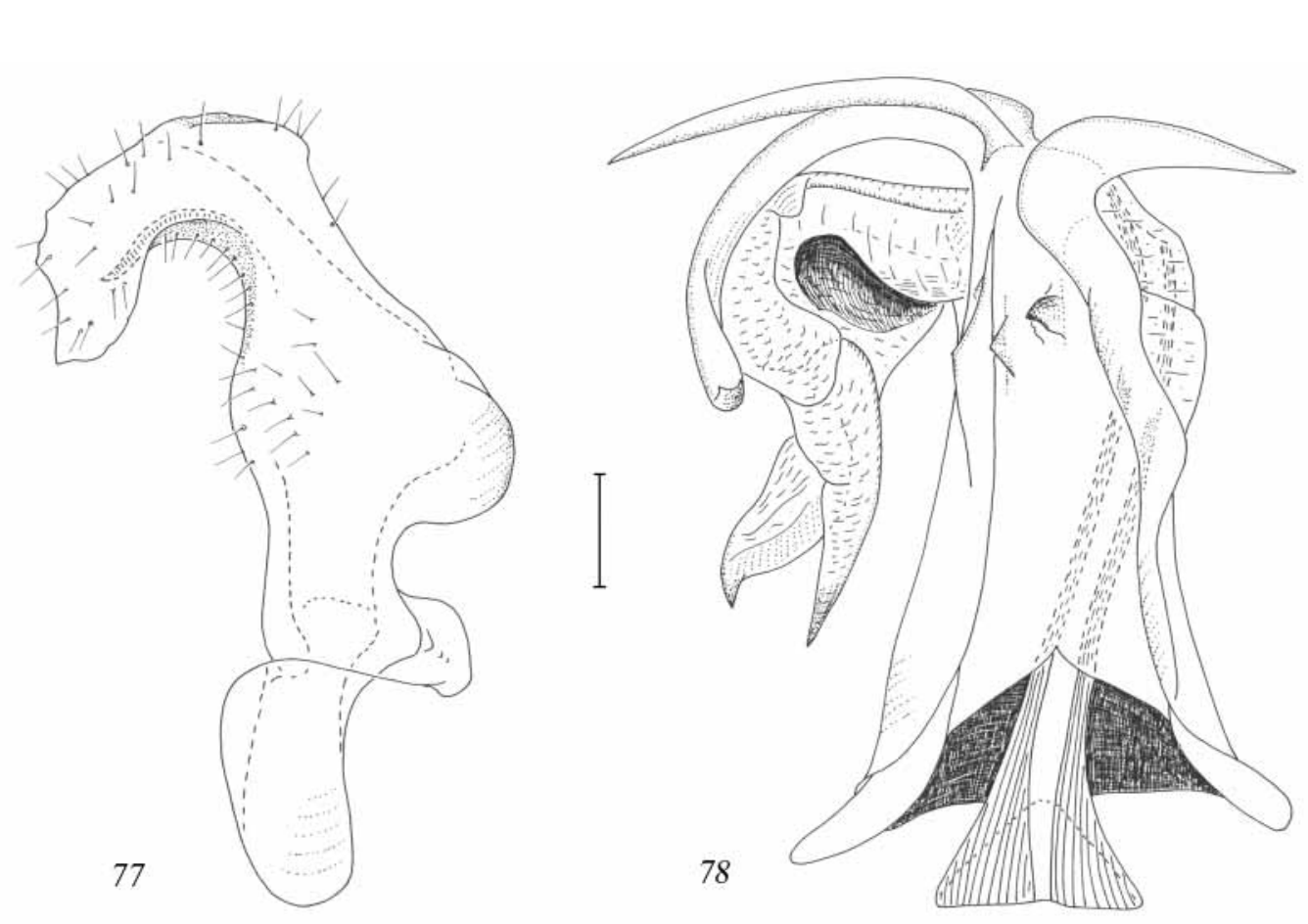

FIGURES 77-78. Oteana omai sp. nov., holotype. Male genitalia. 77, left paramere, maximal aspect; 78, aedeagus, ventral aspect. Scale bar equals $0.1 \mathrm{~mm}$.

Type material.

Holotype ơ: Society Islands: Huahine Island, Mt. Turi, 500 m, at light, 6.-8.IX. 1977, W.C. Gagné leg., BPBM (type nr. 16617). Paratypes: 2 ㅇ, same data as holotype.

\section{Oteana temehani sp. nov.}

(figs 79-84)

Description

Body length. Male. $7.6-8.0 \mathrm{~mm}(+/-0.2) ; \mathrm{n}=3$. Female. $9.0 \mathrm{~mm} ; \mathrm{n}=1$.

Coloration.

Anterior part of vertex and areolets dark brown, posterior corners of vertex stramineous. Frons irregularly testaceous, darkest just above frontoclypeal suture. Postclypeus yellowish, anteclypeus dark brown. Carinae of head yellowish. Pronotum with discoidal and ventral areas dark brown, carinae stramineous. Tegulae stramineous. Mesonotum dark brown with distinct longitudinal stripes: all longitudinal carinae yellowish, area enclosed by lateral carinae on each side testaceous, posterior tip of mesonotum stramineous. Body generally dark brown, legs light brown. Tegmina and wings hyaline, translucent, without conspicuous pattern. Costal vein and pterostigma light 
brown. Venation of tegmina generally yellowish-brown, Y-vein, veins enclosing apical cells and costal vein at junction of Y-vein and costal vein slightly darker.

Proportions and carination of head and thorax as well as spinulation of hind legs as described for the genus.

Male genital complex (figs 79-84)

Genital segment (figs 79, 80) bilaterally asymmetrical, dorsal apical angle of subrectangular lobe on left side more strongly pronounced than on right side (fig. 80, arrow). Subrectangular lobes in lateral aspect slender, gradually tapering. Anal segment (figs 81,82 ) bilaterally symmetrical, broadly ovate. Parameres (fig. 83) distally produced into a pointed tip. Aedeagus (fig. 84): shaft ventrally with 3 spines (a1-a3) and a weakly developed longitudinal ridge (a4?): right lateral spine (a1) compressed, strongly developed, hook-shaped, directed laterad to the right side. Median spines (a2, a3) short, stout, tooth-like, directed straight ventrad and laterad to the left side, respectively. Apical spine of shaft (a5) long, slender, terete, in repose curved laterobasad to left side; subapical spine (a6) strongly developed, taeniform, curved laterad to the left side. Flagellum long, in repose reaching base of shaft, distally bispinose.

Female genitalia as described for the genus.

Etymology

Named for the type locality, Temehani Plateau, on Raiatea.

Distribution

Endemic to Raiatea.

Ecology

Unknown.

Remarks

O. temehani ressembles O. omai from Huahine in external and genital characters; it is distinguished from this species in small, but consistent differences pertaining to the male genital structures, especially the shape of the genital segment (subrectangular process gradually tapering towards apical angle vs. short and stout in $O$. omai) and the aedeagus (e.g., flagellum distinctly longer than in $O$. omai).

Type material

Holotype ${ }^{x}$ : Society Islands: Raiatea Island, Temehani Plateau, 600m, shrub, 1.IX. 1977, B.H. \& W.C. Gagné, S.L. Montgomery leg., BPBM (type nr. 16619). Paratypes: $1 \sigma^{x}$, 1 ㅇ, same data as holotype, BPBM; $1 \overbrace{}^{x}$, same locality as holotype, 500m, at light, 1.4.IX.1977, W.C. Gagné \& S.L. Montgomery leg., BPBM. 


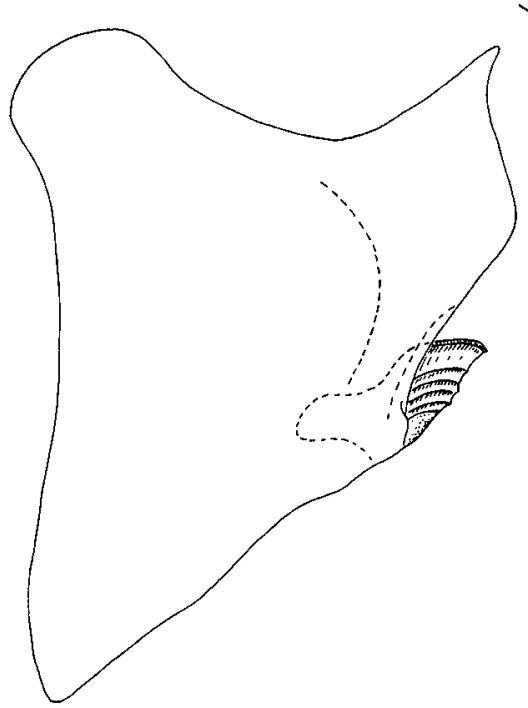

79

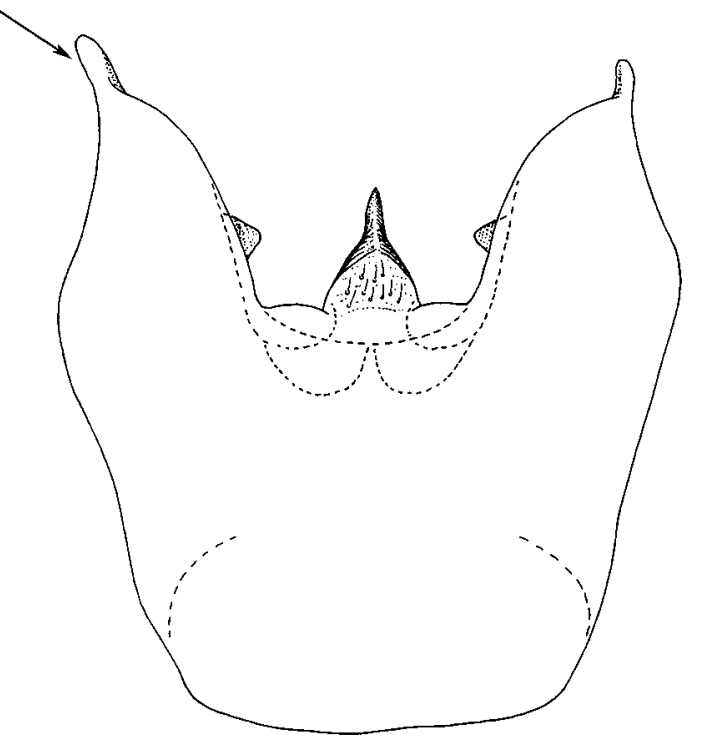

80
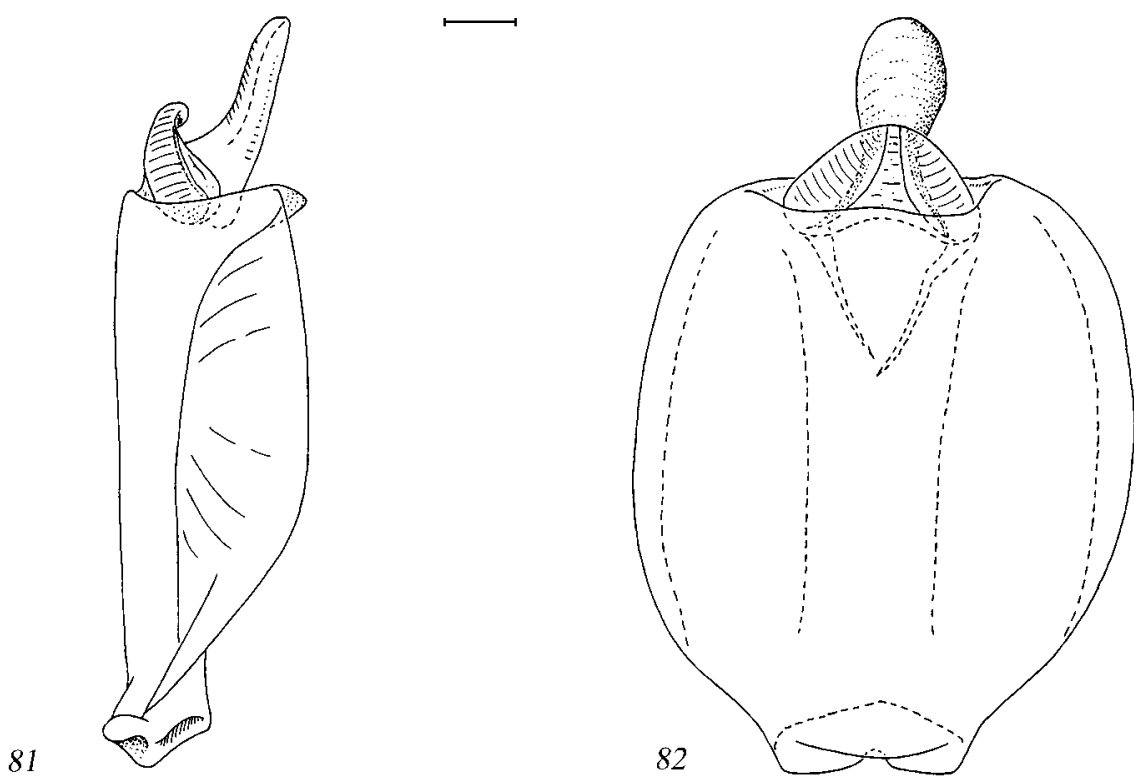

FIGURES 79-82. Oteana temehani sp. nov., holotype. Male genitalia. 79, genital segment, left lateral aspect; 80 , same, ventral aspect; 81, anal segment, left lateral aspect; 82, same, dorsal aspect. Scale bar equals $0.1 \mathrm{~mm}$. 

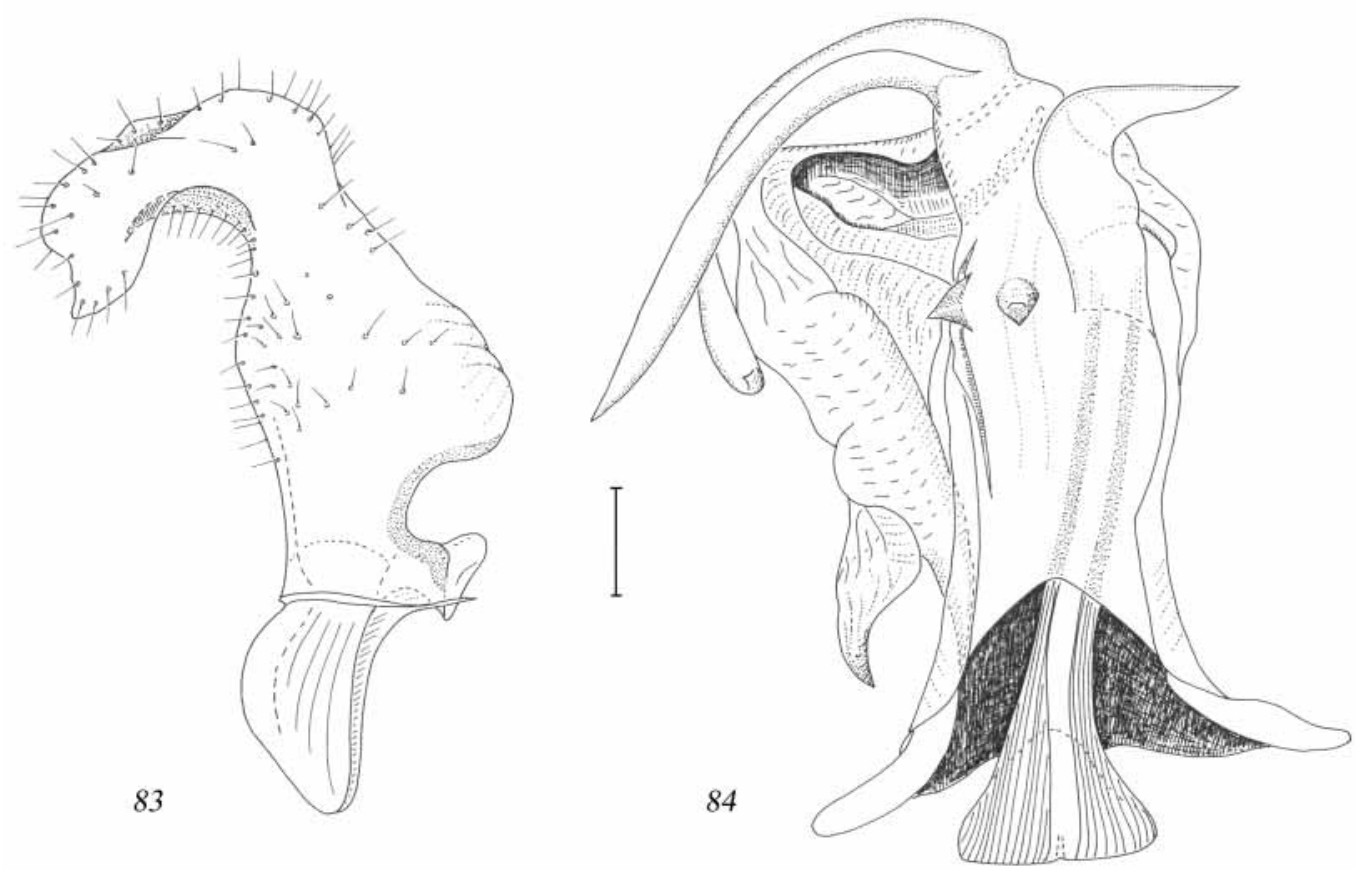

FIGURES 83-84. Oteana temehani sp. nov., holotype. Male genitalia. 83, left paramere, maximal aspect; 84, aedeagus, ventral aspect. Scale bar equals $0.1 \mathrm{~mm}$.

Oteana gemellar (Fennah) comb. nov.

(figs 85-90)

Oliarus gemellar Fennah, 1958: 129

Supplementary description.

Body length.

Male. $6.0 \mathrm{~mm}(\mathrm{n}=1)$. Female. $6.5-6.9 \mathrm{~mm}(\mathrm{n}=3)$.

Proportions and carination of head and thorax, venation of tegmina as well as spinulation of hind tibiae as described for the genus.

\section{Coloration}

Area of vertex and areolets dark brown. Frons stramineous, slightly darker towards vertex, medially with a distinct short dark brown band just above frontoclypeal suture. Anteclypeus and postclypeus in lower part dark brown, lighter brown towards frontoclypeal suture. Carinae of head and fenestrae stramineous. Pronotum with discoidal and ventral areas brownish, posterior margins and carinae stramineous. Mesonotum dark brown, longitudinal carinae, posterior margin and tip stramineous. Mesonotum laterally of outer carinae with a suffusely light brown spot. Body dark brown, legs stramineous. Tegmina hyaline, translucent, without any conspicuous color pattern. Venation 
stramineous, only slightly darker distally. Pterostigma light brown as well as costal vein, the latter only slightly darker around distal margin.

Male genital complex (figs 85-90).

Genital segment (figs 85, 86) bilaterally asymmetrical, laterodorsal angle of subrectangular lobe acute on left side, rounded on right side; medioventral process short, stout, dorsally ridged. Anal segment ( figs 87,88 ) bilaterally symmetrical, broadly ovate. Parameres (fig. 89) with distal portion subapically broadened, tapering apically into an acute tip directed mediobasad, mediodorsal margin slightly serrate. Aedeagus (fig. 90): shaft with 2 ventral and one apical spines: right lateral ventral spine (a1) arising at midlength of shaft, strong, terete, bent at ca. $1 / 2$ its length in a more or less right angle to right side, its tip pointing laterobasad. Left spine (a3) arising slightly distad of base of right lateral spine, slender, curved at ca. 1/3 its length in a more or less right angle to left side, its tip pointing laterad to left side. Apical spine of shaft (a5) arising from a triangular base on apex of shaft, long, slender, distally tapering, curved laterobasad to the left side. Flagellum in repose not reaching base of shaft, distal flagellum spine strong, stout, tip subacute; dorsomedian lobe of flagellum produced into a second strong, apically blunt spinose process, in repose directed mediobasad. Phallotreme wide (fig. 90, arrow), flanked by the two distal flagellum spines.

\section{Distribution}

Endemic to the Cook Islands: Rarotonga.

Ecology

Unknown.

Remarks

O. gemellar can be distinguished from the Society Islands Oteana species by the absence of the subapical aedeagal shaft spine (a6).

Material examined

$1 o^{\star}, 3$ 우, Cook Islands: Rarotonga, Te Kou Plateau, 500m, 2.I.1983, G. Paulay leg., BPBM (compared with holotype; in BPBM). 

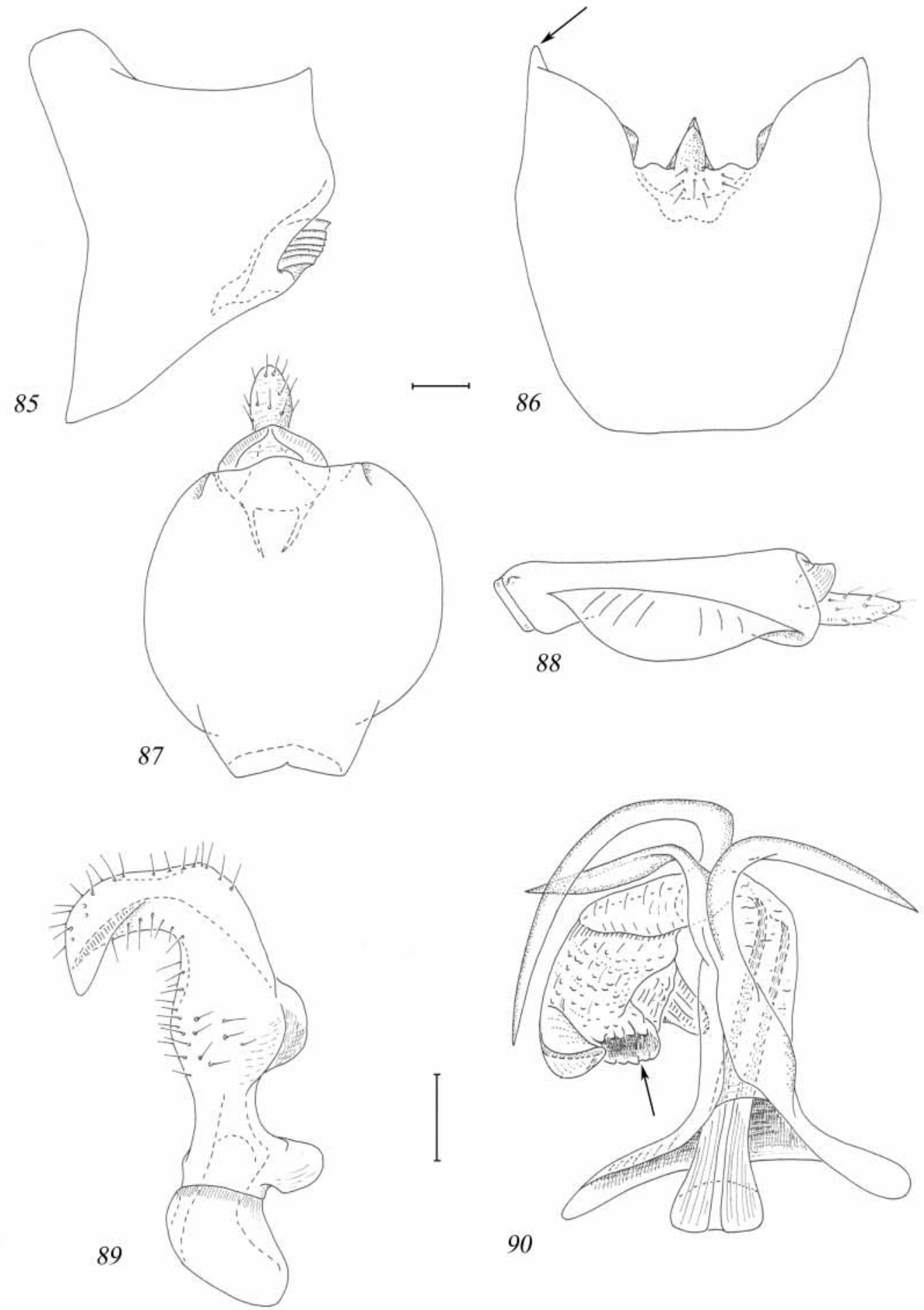

FIGURES 85-90. Oteana gemellar (Fennah, 1958). Male genitalia. 85, genital segment, left lateral aspect; 86, same, ventral aspect; 87, anal segment, dorsal aspect; 88 , same, left lateral aspect; 89, left paramere, maximal aspect; 90, aedeagus, ventral aspect. Scale bars equal $0.1 \mathrm{~mm}$. 
Type species: Manurevana draconarius (Fennah, 1958) comb.nov.

Oliarus draconarius Fennah, 1958: 130

\section{Diagnosis}

Small inconspicuously colored cixiids with depressed body, mesonotum pentecarinate, tegmina shallowly tectiform.

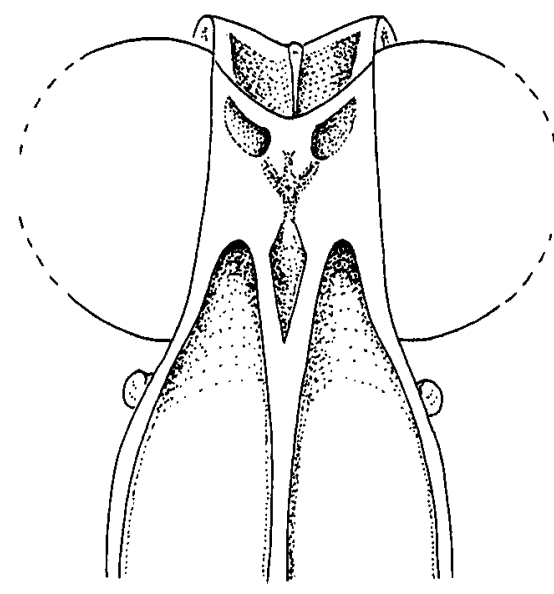

91

FIGURE 91. Manurevana gen.nov.: transition vertex/frons, anterior aspect (M. draconarius (Fennah, 1958), paratype male). Scale bar equals $0.5 \mathrm{~mm}$.

\section{Description}

Head (fig. 91)

Vertex ca. 1.4 times as long as posteriorly wide, in dorsal aspect surpassing the anterior margin of the compound eyes with ca. 1/3 its total length; lateral carinae more or less parallel in posterior half, anteriorly converging, ridged; median carina present in posterior half of vertex; posterior margin of vertex deeply incised. Areolets medially divided by a short, obtuse carina. Transition frons/vertex rounded, without a distinct transverse carina. Frons longish, narrow, ca. 0.8 times as wide as medially long, widest at level of the antennae. Lateral ocelli present, distinct; median frontal ocellus absent. Frontoclypeal suture more or less straight. Frons and clypeus with a ridged median carina, frontal carina forked towards apex. Rostrum attaining metatrochanters. Antennae small, not visible in dorsal aspect, $1^{\text {st }}$ antennal segment short, ring-like, $2^{\text {nd }}$ antennal segment subglobose, irregularly beset with sense organs (plaques).

Thorax.

Pronotum short, posterior margin deeply incised, ca. 1.2 times wider than head, with 
distinct median and lateral carinae. Mesonotum pentecarinate, about as wide as medially long. Tegmina and wings well developed. Tegmina hyaline, translucent, shallowly tectiform, in repose surpassing tip of abdomen with ca. 1/3 their total length. Tegmen ca. 2.5 times longer than maximally wide, apex of outer subapical cell slightly proximad of apex of inner subapical cell, intercubital transverse veinlet entering margin of tegmen distinctly distad of claval suture, longitudinal veins inconspicuously granulate.

Metatibiae laterally with 3 strong spines, distally with (5-)6 spines, arranged in an oblique row, lateral spine more strongly pronounced. Metabasitarsus only slightly longer than $2^{\text {nd }}$ and $3^{\text {rd }}$ metatarsal joints together, distally with (6-)7 spines; $2^{\text {nd }}$ metatarsal joint distally with (7-)8 spines. Metatarsal joints without macrochaetae (platellae).

Male genital complex.

Genital segment bilaterally symmetrical; posterior margin in lateral aspect broadly rounded; medioventral process helmet-shaped, produced with a sharp ridge posteriorly into a pointed tip, dorsally rounded. Anal segment hood-shaped, bilaterally symmetrical, longish ovate, ventrally concave. Parameres in lateral aspect wide at base, distally narrowing and apically broadening into a bluntly triangular portion, medially bearing a strongly developed ridge. Aedeagus. Shaft with two spinose processes. Flagellum long, in repose reaching base of shaft.

Female genitalia.

Caudal margin of 7 th sternite shallowly sinuate, medially slightly convex, produced into a shallow lobe. Ovipositor short, stout, in repose directed straight caudad. $9^{\text {th }}$ tergite truncate, caudally concave, with wax producing area distinct, medially not divided. Anal segment longish ovate, with lateral margins nearly parallel, narrow at base, ventrally not concave.

Etymology

Named for the type locality, Mt. Manureva on Rurutu. The gender is masculine.

Remarks

Manurevana gen.nov. can be distinguished from other pentastirine genera by bodily proportions, shape and arrangement of spines of the metatarsi $(7,8$, no platellae), and the configuration of the male genitalia.

\section{Manurevana draconarius (Fennah, 1958) comb. nov.}

(figs 92-100)

Oliarus draconarius Fennah, 1958: 130

Supplementay description.

Body length.

Male. 4.1 - $4.3 \mathrm{~mm}(\mathrm{n}=4)$. Female. $5.2 \mathrm{~mm}(\mathrm{n}=1)$. 
Coloration.

Area of vertex, areolets, frons, and clypeus dark brown, carination of head stramineous. Pronotum with discoidal and ventral areas brownish, median and lateral carinae as well as posterior margin stramineous. Mesonotum chestnut-brown, longitudinal carinae stramineous. Tegulae stramineous. Tegmina hyaline, translucent, venation stramineous, not contrasting, without any conspicuous color pattern; costal vein slightly darker, pterostigma indistinct. Abdomen dark brown. Legs stramineous.

Proportions and carination of head and thorax, venation of tegmina, as well as spinulation of hind legs as described for the genus.

Male genital complex (figs $92-100$ ).

Genital segment (figs 92, 93), anal segment (figs 94, 95) and parameres (figs 96, 97) as described for the genus. Aedeagus (figs 98 - 100): shaft with a long, compress spine arising at midlength of shaft right laterally, directed apically, curved mediad, and a short, acute spine, arising medioventrally, curved basad. Flagellum with 2 spinose processes: a short, slender, moveable spine arising at flagellum base, in repose directed dorsolaterad, and a long, hook-shaped spine arising left laterally from flagellum base, in repose curved more or less semicircularly mediolaterad to right.

Female genital complex. As described for the genus.

Distribution

Endemic to Austral Islands: Rurutu.

Ecology

Native vegetation in a wet gulch near ridge top, with Cyathea medullaris, Metrosideros collina, Aleurites spec., Cyrtandra elizabethiae, mixed fern understory (D.M. Percy, pers. communication).

Material examined

Holotype ơ: Austral Islands: Rurutu Island, S.W. slope Mt. Manureva, elev. $1000 \mathrm{ft}$, 25.VIII.1934, D. Anderson leg., BPBM (type nr 2627); paratype $0^{x}$ : same data as holotype (except type nr).

Additional material. $3 \sigma^{x}$, Rurutu, Pito ridge track, 17.II. 2003, D. M. Percy leg., BPBM; $3 \sigma^{x}, 2$ ㅇ, Manureva ridge, between Taatioe and Teape, 18.II.2003, D. M. Percy, BPBM. 

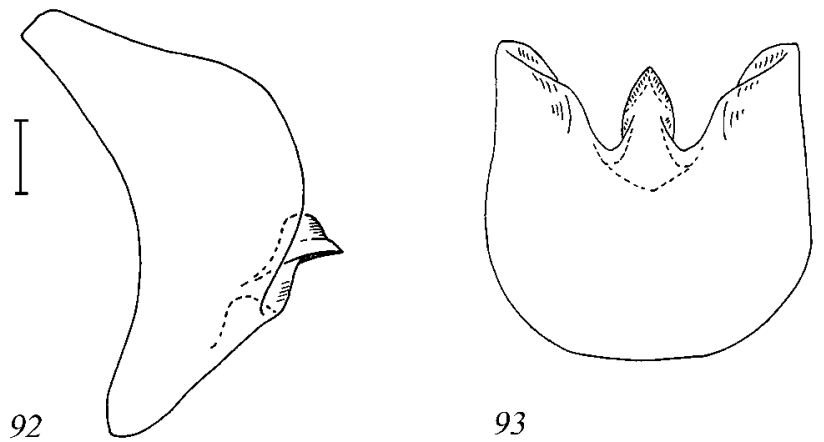

93
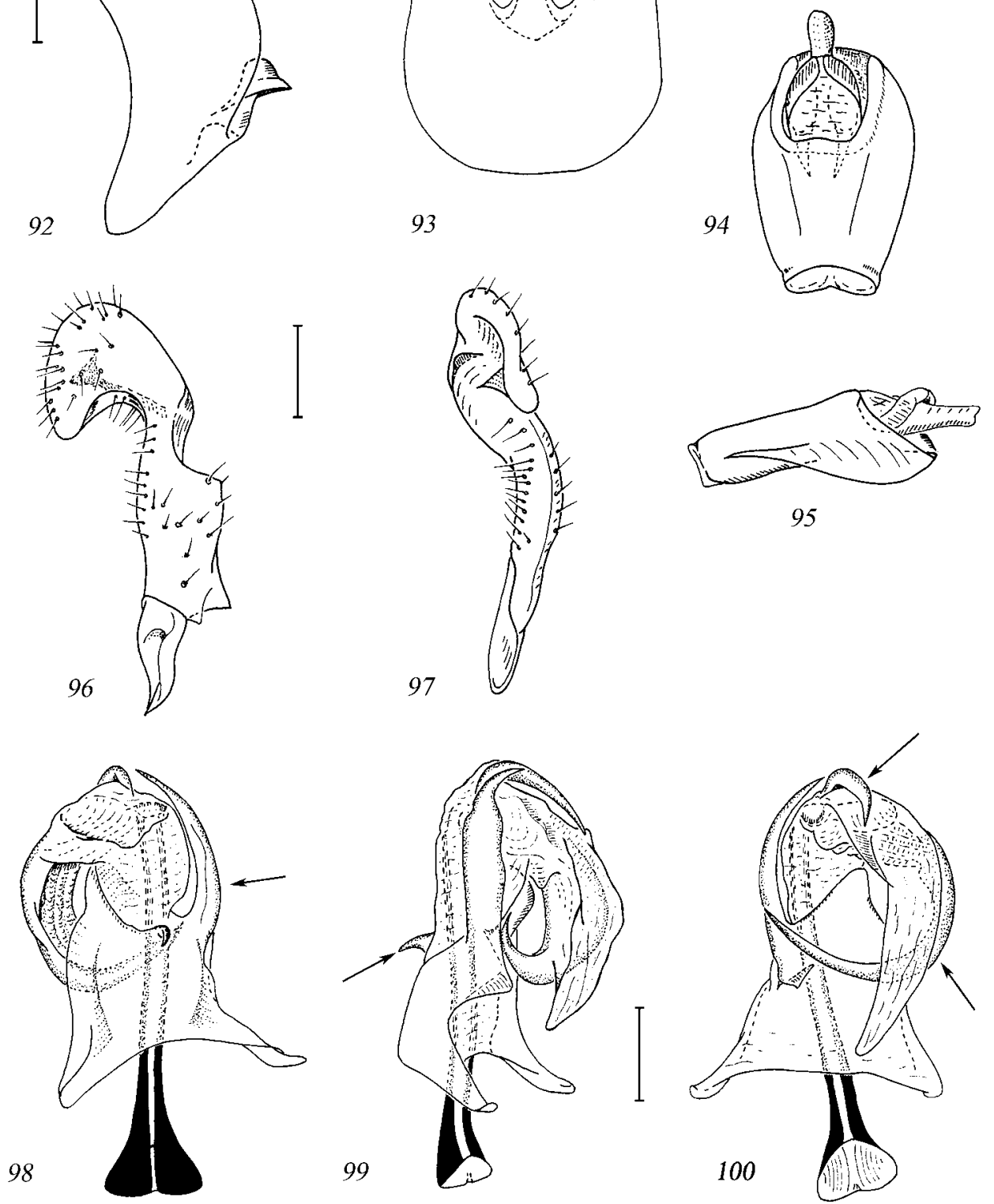

FIGURES 92-100. Manurevana draconarius (Fennah, 1958). Male genitalia. 92, genital segment, left lateral aspect; 93, same, ventral aspect; 94, anal segment, dorsal aspect; 95, same, left lateral aspect; 96, left paramere, maximal aspect; 97, same, dorsal aspect; 98, aedeagus, ventral aspect; 99, same, right lateral aspect; 100, dorsal aspect. Scale bars equal $0.1 \mathrm{~mm}$. 
Based on morphological evidence, the Pentastirini from the Society, Austral, and Cook Islands can be assigned to two distinct morphological groups: Oteana from the Society (Tahiti, Moorea, Huahine, and Raiatea) and Cook Islands (Rarotonga); and Manurevana from the Austral Islands (Rurutu). It is hypothesized here that the two groups represent two separate lineages which independently colonized the islands. Their current biogeographic pattern is characterized by high levels of local endemism: all Oteana and Manurevana species are single-island endemics.

In one of these lineages, Oteana, inter- as well as intra-island speciation is observed. Except for Moorea and Tahiti, the larger and ecologically more diverse islands (which support 2 and 8 species, respectively), the smaller islands (Rarotonga, Huahine, Raiatea) each support only one species.

The other evolutionary lineage, Manurevana, is represented by a single species, Manurevana draconarius, which is endemic to Rurutu, Austral Islands. Certain morphological similarities to the Pentastirini species from the Marquesas Islands (still assigned to "Oliarus"; Fennah 1958) are observed, especially pertaining to the general configuration of the male copulatory organ, the aedeagus. On the basis of the current information, however, it cannot be decided whether Manurevana draconarius is indeed an isolated colonization or part of the radiation observed in the Marquesas Islands.

A comprehensive phylogenetic analysis of the Pentastirini from the Pacific and adjacent continental areas is needed to address the following questions:

Which taxa found on other Pacific Island archipelagos (e.g., the Marquesas, Hawaii) and Pacific rim continental areas (SE-Asia, Australia, South America) are putative adelphotaxa to Oteana and Manurevana?

Which are the likely geographical source areas of the colonizing lineages?

Which speciation patterns underlie the currently observed biogeographic distribution of Oteana species?

The current distribution of Oteana species suggests two major patterns of speciation: progressive colonization from older to younger islands may account for interisland speciation, while (adaptive) radiation may have occurred on Tahiti and, to a lesser degree, on Moorea.

On Tahiti, 5 of the 8 Oteana species occur on Tahiti Nui as well as on Tahitit Iti; only $O$. aorai, O. ata, und $O$. pouvana are known only from Tahiti Nui. The most common and possibly ecologically diverse species is $O$. euphranor, occurring from $600-1650 \mathrm{~m}$ on native vegetation. In the two localities which have been extensively sampled by various 
collectors, Mt. Aorai (Tahiti Nui) and around Vaiufaufa viewpoint on Tahiti Iti, $O$. euphranor co-occurs with 7 (and 4, respectively) other Oteana species. There appears to be no obvious evidence for ecological differentiation (e.g., host plant or macrohabitat preference or altitudinal zonation) of the adults. It is conceivable, however, that the nymphal stages which-like all cixiid nymphs-live underground, have specialized to adapt to particular hosts. An alternative model to autochthoneous radiation are repeated cycles of colonization and subsequent speciation. Eventually, the co-occurrence of as much as eight Oteana species on Mt Aorai could even be the result of anthropogenic influence: As the native vegetation in lower altitudes (below ca. $900 \mathrm{~m}$ ) has been significantly altered by invading plant species (most prevalent on Tahiti: by Miconia calvescens (Melastomaceae; see Mueller-Dombois \& Fosberg [1998]), Oteana species which may have originally inhabited lower altitude plant communities may have been forced to seek refuge at higher altitudes where native vegetation is still extant. Similar phenomena have been observed in Hawaii (see Cuddihy \& Stone 1990).

\section{Acknowledgements}

I would like to express my sincere thanks to G.M. Nishida, Essig Museum of Natural History, Berkeley, California, and A. Ramsdale, former collection managers at Bishop Museum, Honolulu, and to D.M. Percy, University of British Columbia, Vancouver, for loan of material. I am also very grateful to N. Hoff, graphic artist, Museum für Naturkunde, Berlin, for providing the habitus drawing; and to V. Hartung and A. Wessel, who kindly helped with image processing. A great big mahalo goes to M. Asche, Museum für Naturkunde, Berlin, for his constructive criticism of the manuscript, for his advice, and for his encouragement whenever the going gets tough. This publication is a contribution to the "Biodiversity and Evolution of Fulgoromorpha"-a global Research Initiative (BEFRI) (http://bach.snv.jussieu.fr/befri/).

\section{References}

Craig, D.A., Currie, D.C. \& Deidre, A.J. (2001) Geographical history of the central-western Pacific black fly subgenus Inseliellum (Diptera : Simuliidae : Simulium) based on a reconstructed phylogeny of the species, hot-spot archipelagos and hydrological considerations. Journal of Biogeography, 28, 1101-1127.

Cuddihy, L.W. \& Stone, C.P. (1990) Alteration of Native Hawaiian Vegetation. University of Hawaii Press, Honolulu, Hawaii, 138 pp.

Emeljanov, A.F. (2001a) The generic position of some Nearctic Pentastirini (Homoptera: Fulgoroidea: Cixiidae). Zoosystematica Rossica, 9(1), 122.

Emeljanov, A.F. (2001b) The genus Oliarus s.str. and related genera from the Oriental Region (Homoptera: Cixiidae). Zoosystematica Rossica, 10(1), 71-72.

Fennah, R.G. (1958) Fulgoroidea of South-Eastern Polynesia. The Transactions of the Royal Ento- 
mological Society of London, 110(6), 117-220.

Fennah, R.G. (1973) The cavernicolous fauna of Hawaiian lava tubes. 4. Two new blind Oliarus (Fulgoroidea Cixiidae). Pacific Insects, 15, 181-184.

Giffard, W.M. (1925) A review of the Hawaiian Cixiidae, with descriptions of species (Homoptera). Proceedings of the Hawaiian Entomological Society, 6, 1-121.

Hoch, H. (2005) On the identity of the type species of the planthopper genus Oliarus Stål, 1862, Oliarus walkeri (Stål, 1859) (Hemiptera: Cixiidae). Zootaxa, 1056, 53-60.

Hoch, H. \& Howarth, F.G. (1999) Multiple cave invasion by the species of the cixiid planthopper Oliarus in Hawaii. Zoological Journal of the Linnaean Society, 127, 453-475.

Holzinger, W.E., Emeljanov, A.F. \& I. Kammerlander (2002) The family Cixiidae Spinola 1839 (Hemiptera: Fulgoromorpha) - a review. pp. 113-138. In: Zikaden. Leafhoppers, planthoppers and ciadas (Insecta: Hemptera: Auchenorrhyncha) (ed. by W. Holzinger \& F. Gusenleitner). Denisia 4, Katalog des OÖ. Landesmuseums, 176, Linz, Austria.

Mueller-Dombois, D. \& Fosberg, F.R. (1998) Vegetation of the Tropical Pacific Islands. Springer, New York, Berlin, 733 pp.

Van Stalle, J. (1986a) Revision of the afrotropical Pentastirini (Homoptera, Cixiidae). III. Norialsus gen. nov. Journal of the Entomological Society of South Africa, 49, 197-230.

Van Stalle, J. (1986b) Revision of the afrotropical Pentastirini (Homoptera, Cixiidae). IV. Description of Peartolus gen. nov., Dorialus gen. nov., Narravertus gen. nov., Kibofascius gen. nov., Afroreptalus gen. nov. and Pseudoliarus hudeibensis n.sp. with notes on phylogeny and systematics. Academiae analecta, 48, 99-129.

Van Stalle, J. (1986c) Helenolius, a cixiid bug genus endemic to St Helena (Insecta: Homoptera). Journal of Natural History, 20, 273-278.

Zimmerman, E.C. (1948) Insects of Hawaii. Vol. 4. Homoptera: Auchenorrhyncha. University of Hawaii Press, Honolulu, Hawaii. 